OPEN ACCESS

Edited by: Rajeev K. Singla,

West China Hospital, Sichuan University, China

Reviewed by:

Shikha Joon,

Jawaharlal Nehru University, India Manoj Kumar Sabnani, Alloy Therapeutics, Inc., United States

*Correspondence: Anupam Bishayee abishayee@lecom.edu abishayee@gmail.com Mohammad Hosein Farzaei mh.farzaei@gmail.com

Specialty section: This article was submitted to Ethnopharmacology, a section of the journal Frontiers in Pharmacology

Received: 10 December 2020 Accepted: 28 January 2021 Published: 29 March 2021

Citation: Ghanbari-Movahed M, Jackson G, Farzaei MH and Bishayee A (2021) A Systematic Review of the Preventive and Therapeutic Effects of Naringin

Against Human Malignancies.

Front. Pharmacol. 12:639840. doi: 10.3389/fphar.2021.639840

\section{A Systematic Review of the Preventive and Therapeutic Effects of Naringin Against Human Malignancies}

\author{
Maryam Ghanbari-Movahed ${ }^{1,2}$, Gloria Jackson ${ }^{3}$, Mohammad Hosein Farzaei ${ }^{1 *}$ and \\ Anupam Bishayee ${ }^{3 *}$
}

\begin{abstract}
${ }^{1}$ Medical Technology Research Center, Health Technology Institute, Kermanshah University of Medical Sciences, Kermanshah, Iran, ${ }^{2}$ Department of Biology, Faculty of Science, University of Guilan, Rasht, Iran, ${ }^{3}$ Lake Erie College of Osteopathic Medicine, Bradenton, FL, United States
\end{abstract}

Background: Natural product-based cancer preventive and therapeutic entities, such as flavonoids and their derivatives, are shown to have a noticeable capability to suppress tumor formation and cancer cell growth. Naringin, a natural flavanone glycoside present in various plant species, has been indicated to modulate different signaling pathways and interact with numerous cell signaling molecules, which allows for an extensive variety of pharmacological actions, such as amelioration of inflammation, oxidative stress, metabolic syndromes, bone disorders, and cancer. The purpose of this systematic review is to present a critical and comprehensive assessment of the antitumor ability of naringin and associated molecular targets in various cancers.

Methods: Studies were identified through systematic searches of Science Direct, PubMed, and Scopus as well as eligibility checks according to predefined selection criteria.

Results: Eighty-seven studies were included in this systematic review. There was strong evidence for the association between treatment with naringin alone, or combined with other drugs and antitumor activity. Additionally, studies showed that naringin-metal complexes have greater anticancer effects compared to free naringin. It has been demonstrated that naringin employs multitargeted mechanisms to hamper cancer initiation, promotion, and progression through modulation of several dysregulated signaling cascades implicated in cell proliferation, autophagy, apoptosis, inflammation, angiogenesis, metastasis, and invasion.

Conclusion: The results of our work show that naringin is a promising candidate for cancer prevention and treatment, and might offer substantial support for the clinical application of this phytocompound in the future. Nevertheless, further preclinical and clinical studies as well as drug delivery approaches are needed for designing novel formulations of naringin to realize the full potential of this flavonoid in cancer prevention and intervention.

Keywords: citrus fruits, naringin, cancer, therapy, molecular mechanisms, prevention 


\section{INTRODUCTION}

Cancer is a set of complex processes, including unlimited cell proliferation, death of impaired cells, and spatial-temporal changes in cell physiology, that may result in the formation of malignant tumors with the potential for metastasis (Seyfried and Shelton, 2010). There are many different approaches for the treatment of cancer, but some may be ineffective due to increased resistance to classical anticancer drugs as well as adverse side effects (Abotaleb et al., 2019).

Scientific reports and traditional knowledge demonstrate that a high intake of fruits and vegetables is constantly associated with a decreased risk of some type of human cancers, such as lung, colon, prostate, and breast cancer (Neuhouser, 2004). Fruit-based cancer preventive and therapeutic entities, such as flavonoid and their derivatives, have shown a noticeable capability to suppress tumor formation and cancer cell growth (Ramesh and Alshatwi, 2013). Flavonoids are a big class of natural polyphenols, existing in a broad variety of vegetables and fruits commonly consumed by humans. These phytochemicals are divided into different subclasses, including flavonols, flavan-3-ols, isoflavones, flavanones, anthocyanidins, and flavones (Romagnolo and Selmin, 2012). In the context of carcinogenesis, flavonoids intervene with multiple signal transduction cascades and increase apoptosis as well as inhibit metastasis, angiogenesis, and proliferation (Ravishankar et al., 2013).

Naringin, a flavanone glycoside derived from the flavanone naringenin, is present in many plant species, especially citrus fruits (Zhang et al., 2014). It has been indicated to interact with a wide range of signaling molecules and modulate various signaling pathways and thus has multiple pharmacological impacts, such as antioxidant, antiinflammatory, antiapoptotic, antitumor, and antiviral properties as well as effects on metabolic syndrome, bone regeneration, neurodegenerative disorders, cardiovascular disease, and genetic damage (Bharti et al., 2014; Chen et al., 2016; Joshi et al., 2018; Rivoira et al., 2020). Notably, previous studies have demonstrated that high dietary intake of naringin reduced the risk of certain cancers, such as lung cancer (Le Marchand et al., 2000). Although a few reports exist on the overview of naringin in cancer, these publications are narrative reviews or reviews of the pharmacological activities of naringin without particular emphasis on its antitumor effects and none of them have evaluated naringin individually in the prevention and treatment of cancer (Meiyanto et al., 2012; Rivoira et al., 2020; Memariani et al., 2020). Hence, a critical and comprehensive systematic review on the anticancer ability of naringin and associated molecular targets within different cancers has not been conducted in the past. Accordingly, the objective of this article is to present a critical and up-to-date systematic evaluation of the preventive and therapeutic impacts of naringin and associated cellular and molecular mechanisms of action.

\section{NATURAL PRODUCTS AND MALIGNANCIES}

It is known that throughout history, natural products have played an important role in health promotion and disease prevention. Natural products represent a valuable resource in the development and discovery of new drugs, particularly those used for cancer treatment (Newman and Cragg, 2012; Cragg and Pezzuto, 2016; Newman and Cragg, 2020). A large number of the significant advances in cancer treatment are directly associated with the development of natural product-based drugs and the use of these agents to suppress, reverse, or retard the process of carcinogenesis (Cragg and Pezzuto, 2016). Many natural products from herbs, vegetables, plant extracts, and fruits exert chemoprotective properties against carcinogenesis (Amin et al., 2009; Gullett et al., 2010; Lee et al., 2011; Bishayee and Sethi, 2016). Plant secondary metabolites, also known as phytochemicals, belong to four major classes, such as terpenoids, phenolics, alkaloids, and sulfur-containing compounds. A large number of these phytocompounds are strong antioxidants as well as antiinflammatory agents with reactive groups that confer protective activities. The vast majority of the non-nutrient antioxidants present in various plants are phenolic compounds, including catechins in tea, isoflavones in soybeans, phenolic esters in coffee, quercetin in onions, phenolic acid in red wine, and rosmarinic acid in rosemary (Sheikh et al., 2021). Flavonoids, a subclass of polyphenols, have also been demonstrated to block the cell cycle progression, protect cells from damage due to external factors, suppress mutations, inhibit prostaglandin synthesis, and inhibit carcinogenesis in animal models (Abdulla and Gruber, 2000). Several animal studies have shown a protective effect for isoflavonoids against mammary cancers (Steiner et al., 2008; Basu and Maier, 2018; Ávila-Gálvez et al., 2020). A high isoflavone diet has also been indicated to suppress tumorigenesis in various animal models for prostate cancer (Persky et al., 1994). Multiple lines of experimental evidences suggest that treatment with naringenin or novel naringenin formulations could inhibit various malignancies, such as melanoma, breast, and cervical cancer (Krishnakumar et al., 2011; Rajamani et al., 2018; Choi et al., 2020). Tea is an essential source of flavonols and flavanols. Many experimental studies show an anticancer effect for tea polyphenols (Yang et al., 2001). It has also been indicated that administration of genistein early in life increases the differentiation and early maturation of the rat mammary gland (Persky et al., 1994), conferring protection against breast cancer. Although synthetic cancer drugs cause non-specific cell killing, natural products,

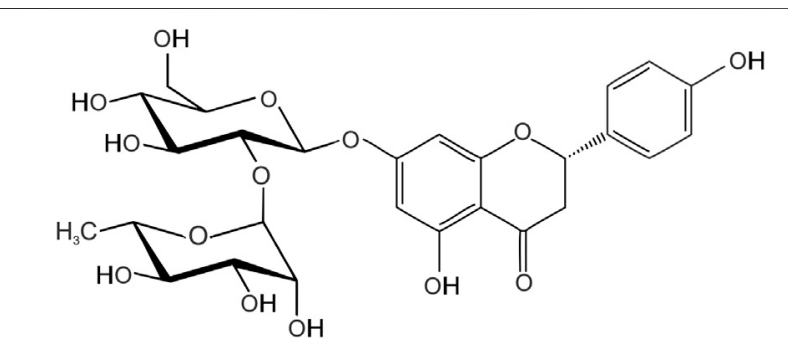

FIGURE 1 | The chemical structure of naringin. 
TABLE 1 | Various natural sources of naringin.

\begin{tabular}{|c|c|c|}
\hline Source plant & Naringin content $(\mu \mathrm{g} / \mathrm{ml})$ & References \\
\hline Citrus $\times$ aurantium L. [Rutaceae] & 19.7 & Kawaii et al. (1999) \\
\hline Citrus $\times$ limon (L.) Osbeck [Rutaceae] & 22.3 & Kawaii et al. (1999) \\
\hline Citrus deliciosa Ten. [Rutaceae] & 8.0 & Dhuique-Mayer et al. (2005) \\
\hline Citrus medica L. [Rutaceae] & 18.6 & Menichini et al. (2016) \\
\hline Citrus $\times$ aurantium L. [Rutaceae] & 230.0 & Kawaii et al. (1999) \\
\hline Citrus $\times$ aurantium L. [Rutaceae] & 3383.6 & de Lourdes Mata Bilbao et al. (2007) \\
\hline Citrus $\times$ aurantium L. [Rutaceae] & 21.3 & Ooghe et al. (1994) \\
\hline
\end{tabular}

TABLE 2 | Description of population, intervention, comparator, outcome and study design (PICOS).

\section{Population}

Intervention

Comparison

Outcome

Study design
- Normal and cancer cell lines

- Healthy and tumor bearing animals

- Naringin

- $\Delta$-changes between treatments (naringin/control/anticancer drug)

- Effect of naringin on cancer cell growth inhibition and/or reduction of tumor size and volume

- In vitro studies

- In vivo studies including dietary phytochemicals, offers therapeutic and protective activities with low cytotoxicity (Reddy et al., 2003).

\section{NARINGIN: SOURCES, CHEMISTRY, AND PHARMACOLOGY}

Naringin, chemically known as 4',5,7-trihydroxyflavanone-7rhamnoglucoside $\left(\mathrm{C}_{27} \mathrm{H}_{32} \mathrm{O}_{14}\right.$, molecular weight: 580.5, Figure 1), is a flavone glycoside that is present in many plant species, particularly citrus fruits, with remarkable pharmacological and biological activities. It is one of the main active components of various Chinese herbal medicines, such as Citrus medica L. (CM) and Citrus aurantium L. (CA) (Table 1) (Alam et al., 2014; Zhang et al., 2014). The chemical structure of naringin was first annotated in 1928 by Inubuse and Asahina (EFSA, 2011). In one study, naringin was isolated from $C$. aurantium crude peel extract after HPLC separation and its structure was confirmed by electrospray ionization mass spectrometry. The predicted mass for naringin was $580 \mathrm{Da}$ (Zhang et al., 2018a). Naringin is derived from naringenin and is responsible for the bitterness of citrus fruits and their products (Konno et al., 1982). It can be hydrolyzed by rhamnosidase activity of naringinase into prunin and rhamnose, which can be further hydrolyzed by the b-D-glucosidase component of naringinase, into naringenin and glucose (Real et al., 2007).

Naringin has been shown to modulate various enzyme and protein expressions, thus exerting potential therapeutic activities. Naringin has been demonstrated to significantly affect cell proliferation and osteogenic differentiation (Dai et al., 2009). Naringin has also been indicated to be effective in decreasing the expression of numerous signaling factors involved in the inflammatory response, e.g., interleukin-8 (IL-8), tumor necrosis factor- $\alpha$ (TNF- $\alpha$ ), interleukin-6 (IL-6), inducible nitric oxide synthase (iNOS), and nuclear factor erythroid 2-related factor 2 (Nrf2) (Habauzit et al., 2011). It has also been reported to decrease metabolic syndrome through downregulation of the expression of key gluconeogenic enzymes and upregulation of AMP-activated protein kinase. Additionally, it decreases the activity of 3-hydroxy-3-methylglutaryl coenzyme A reductase and enhances the production of nitric oxide metabolites. Naringin also shows antigenotoxic actions and decreases DNA damage by controlling the generation of free radicals and the expression of oxidative mediators (Chen et al., 2016). It has beneficial effects on many central nervous system diseases, including epilepsy, Parkinson's disease, and Alzheimer's disease (Jäger and Saaby, 2011), and has been demonstrated to have dose-dependent radical scavenging activity and decreased oxidative stress (Rajadurai and Prince, 2007). Overall, naringin can be regarded as a promising natural compound that elicits various health benefits.

\section{METHODOLOGY FOR LITERATURE SEARCH ON NARINGIN AND MALIGNANCIES}

\section{Search Strategy}

The current systematic review was conducted following the Preferred Reporting Items for Systematic Reviews and Meta-Analysis (PRISMA) guidelines (Moher et al., 2009), employing several electronic databases (Science Direct, PubMed, and Scopus) and using the following keywords: "naringin" AND ("neoplasm" OR "cancer" OR "tumor" OR "carcinoma" OR "malignancy"). The information about populations, interventions, comparators, outcomes, and study designs (PICOS) criteria are presented in Table 2.

\section{Inclusion Criteria}

Experimental studies (in vivo and in vitro) up to September 2020 in the English language which assessed the anticancer effect of naringin (in any cancer cell line and/or animal model) were included. 


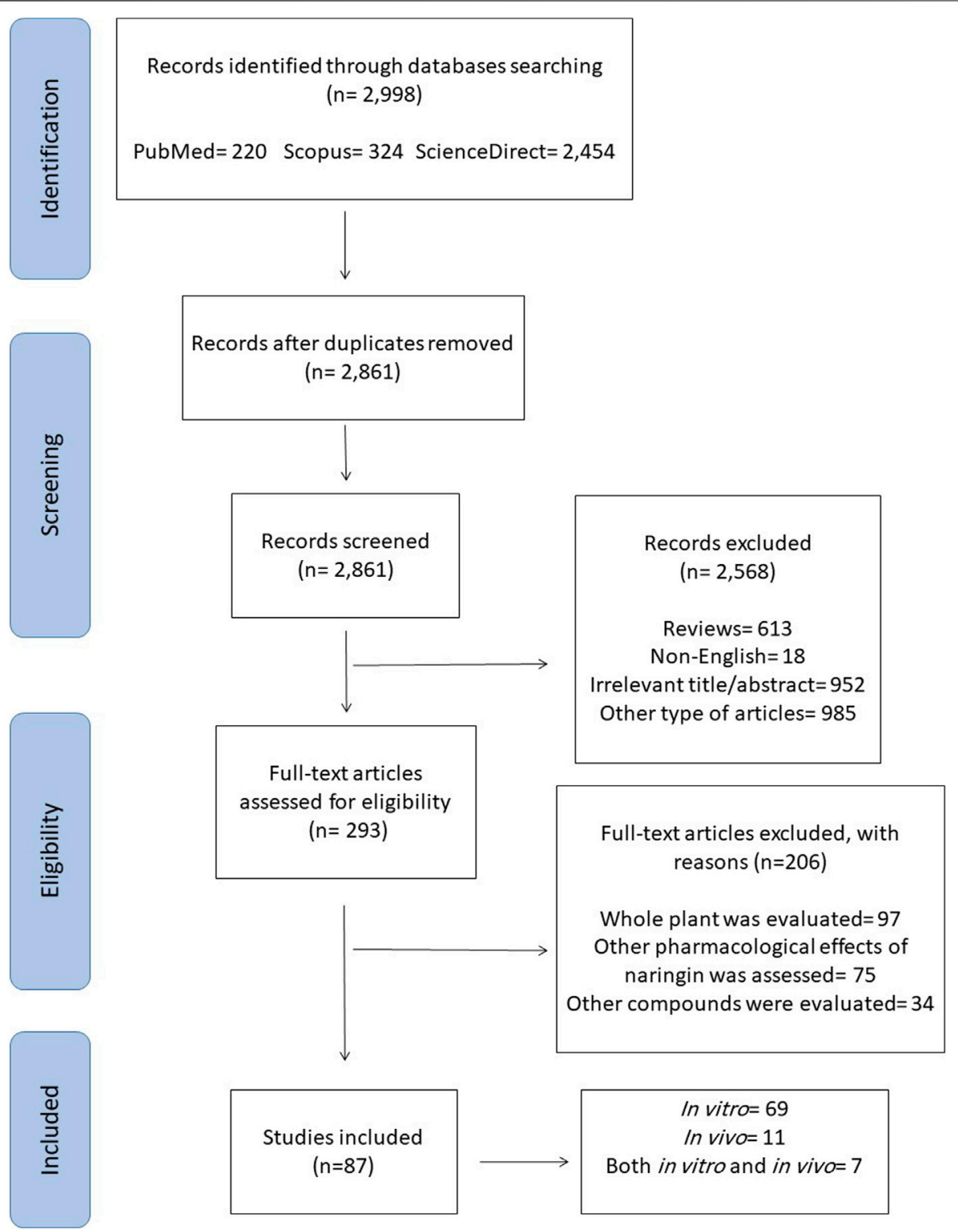

FIGURE 2 | The PRISMA flow chart of the selection process for the included studies.

\section{Exclusion Criteria}

We applied the following exclusion criteria: 1) conference abstracts, books, book chapters, and unpublished results; 2) non-English papers; 3) reviews, systematic reviews, metaanalysis, and letters; 4) primary research papers that do not involve tumor cell lines or animal tumor models.

\section{Data Extraction}

Among the initial 2,998 reports that were collected through electronic search, 137 were omitted due to duplicated results, 985 were ruled out because of the article type, 613 review articles were omitted, and 952 were deemed irrelevant based on abstract and/or title information. Besides, 18 were excluded because they were not in English language. Out of 293 retrieved reports, 97 were excluded as they evaluated the whole plant, 75 were ruled out as they examined other biological impacts of naringin rather than anticancer effects, and 34 were excluded because they concentrated on other compounds, not naringin.

\section{Data Synthesis}

Finally, 87 articles were included in this study as demonstrated in a flowchart of the literature search and selection process (Figure 2). It was envisioned that studies would be too heterogeneous to be combined. Hence, a narrative synthesis was conducted. The results are summarized according to type of cancer and outcome measures assessed. The magnitudes of effects on each outcome measure are reported. 
TABLE 3 | Potential anticancer effects and related mechanisms of action of naringin based on in vitro studies.

\begin{tabular}{|c|c|c|c|c|c|c|c|c|}
\hline $\begin{array}{l}\text { Cancer } \\
\text { type }\end{array}$ & $\begin{array}{l}\text { Cell } \\
\text { type }\end{array}$ & Conc & Source & $\begin{array}{c}\text { Purity } \\
\text { (\%) }\end{array}$ & $\begin{array}{l}\text { Quality } \\
\text { control } \\
\text { reported? } \\
\text { (Y/N) }\end{array}$ & Duration & $\begin{array}{c}\text { Anticancer } \\
\text { effects }\end{array}$ & References \\
\hline Bladder & $\begin{array}{l}\text { T24 and } \\
5,637 \text { cell } \\
\text { lines }\end{array}$ & $50-150 \mu \mathrm{M}$ & $\begin{array}{l}\text { Wako pure chemical } \\
\text { Industries, Itd. (Osaka, } \\
\text { Japan) }\end{array}$ & ND & Y & $24 \mathrm{~h}$ & $\begin{array}{l}\downarrow \text { Cell proliferation, } \\
\downarrow \text { cell viability, } \downarrow \text { cell } \\
\text { growth, } \uparrow \text { cell cycle } \\
\text { arrest, } \uparrow 21 \text { WAF1, } \\
\uparrow \text { Ras, } \uparrow \text { Raf }\end{array}$ & Kim et al. (2008) \\
\hline Bladder & TCC cell line & $0.3-5 \mu \mathrm{M}$ & $\begin{array}{l}\text { Merck Chemical Co. } \\
\text { (Darmstadt, Germany) }\end{array}$ & ND & Y & $24-48 \mathrm{~h}$ & $\begin{array}{l}\downarrow \text { Cell proliferation, } \\
\downarrow \text { cell viability }\end{array}$ & $\begin{array}{l}\text { Karami et al. } \\
(2018)\end{array}$ \\
\hline Bladder & TCC cell line & $75 \mu \mathrm{g} / \mathrm{ml}$ & $\begin{array}{l}\text { Sigma-Aldrich } \\
\text { (Munich, Germany) }\end{array}$ & ND & Y & $24-72 \mathrm{~h}$ & $\begin{array}{l}\downarrow \text { Cell proliferation, } \\
\downarrow \text { cell viability }\end{array}$ & $\begin{array}{l}\text { Oršolić et al. } \\
(2009)\end{array}$ \\
\hline Blood (leukemia) & $\begin{array}{l}\text { HL-60, } \\
\text { Kasumi-1, } \\
\text { and K562 } \\
\text { cell lines }\end{array}$ & $0.125-2 \mathrm{mg} / \mathrm{ml}$ & $\begin{array}{l}\text { China Institute of } \\
\text { drugs and } \\
\text { Bioproducts (Beijing, } \\
\text { China) }\end{array}$ & ND & Y-HPLC & $24-48 h$ & $\begin{array}{l}\downarrow \text { Cell proliferation, } \\
\uparrow \text { apoptosis, } \downarrow \text { Mcl-1 }\end{array}$ & Dai et al. (2017) \\
\hline Blood (leukemia) & U937 cell line & $50-500 \mu \mathrm{M}$ & $\begin{array}{l}\text { Sigma-Aldrich (Lyon, } \\
\text { France) }\end{array}$ & (90\%) & Y & $24 \mathrm{~h}$ & $\begin{array}{l}\downarrow \text { Cell proliferation, } \\
\downarrow \text { cell growth, } \uparrow \text { cell } \\
\text { death }\end{array}$ & Jin et al. (2009) \\
\hline Blood (leukemia) & $\begin{array}{l}\text { THP-1 cell } \\
\text { line }\end{array}$ & $50-400 \mu \mathrm{M}$ & $\begin{array}{l}\text { Gibco BRL } \\
\text { (Gaithersburg, MD, } \\
\text { United States) }\end{array}$ & ND & Y & $48 \mathrm{~h}$ & $\begin{array}{l}\downarrow \text { Cell proliferation, } \\
\downarrow \text { cell viability }\end{array}$ & Park et al. (2008) \\
\hline Blood (leukemia) & $\begin{array}{l}\text { HL-60 and } \\
\text { THP-1 cell } \\
\text { lines }\end{array}$ & $40-80 \mu \mathrm{M}$ & $\begin{array}{l}\text { Sigma-Aldrich (Lyon, } \\
\text { France) }\end{array}$ & ND & Y & $6-24 h$ & No effect & Chen et al. (2003) \\
\hline Blood (leukemia) & K562 cell line & $5-500 \mu \mathrm{M}$ & $\begin{array}{l}\text { Quinabra Company } \\
\text { (São José dos } \\
\text { Campos, Brazil) }\end{array}$ & ND & Y & $24-72 \mathrm{~h}$ & $\begin{array}{l}\downarrow \text { Cell number, } \downarrow \text { cell } \\
\text { growth, } \uparrow \text { cell death, } \\
\downarrow \text { DPPH }\end{array}$ & $\begin{array}{l}\text { Pereira et al. } \\
(2007)\end{array}$ \\
\hline Blood (leukemia) & K562 cell line & $1-100 \mu \mathrm{M}$ & $\begin{array}{l}\text { Fluka chemie GmbH } \\
\text { (Buchs, Switzerland) }\end{array}$ & $(\geq 95 \%)$ & Y-TLC and HPLC & $20-100 \mathrm{~h}$ & $\downarrow V E G F$ & $\begin{array}{l}\text { Mellou et al. } \\
(2006)\end{array}$ \\
\hline Blood (lymphoma) & $\begin{array}{l}\text { P-388D1, L- } \\
1210 \text { cell } \\
\text { lines }\end{array}$ & $1-2 \mathrm{mM}$ & $\begin{array}{l}\text { Sigma-Aldrich } \\
\text { (St. Louis, MO, USA) }\end{array}$ & ND & Y & $12 \mathrm{~h}$ & 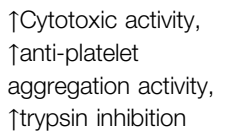 & Kim et al. (1998) \\
\hline Blood (lymphoma) & Raji cell line & $10-1,000 \mu \mathrm{M}$ & $\begin{array}{l}\text { Extrasynthese-Genay } \\
\text { (Lyon, France) }\end{array}$ & ND & Y & $24 \mathrm{~h}$ & $\begin{array}{l}\downarrow \text { Cell proliferation, } \\
\downarrow \text { cell growth }\end{array}$ & $\begin{array}{l}\text { Ramanathan et al. } \\
\text { (1992) }\end{array}$ \\
\hline Brain & U-87cell line & $5-30 \mu \mathrm{M}$ & $\begin{array}{l}\text { Sigma-Aldrich (Lyon, } \\
\text { France) }\end{array}$ & (98\%) & Y & $24-48 \mathrm{~h}$ & $\begin{array}{l}\downarrow \text { Cell proliferation, } \\
\downarrow \text { cell viability, } \downarrow \text { cell } \\
\text { invasion, } \\
\downarrow \text { tubulogenesis }\end{array}$ & Aroui et al. (2020) \\
\hline Brain & $\begin{array}{l}\text { U87 and } \\
\text { U251 cell } \\
\text { lines }\end{array}$ & $10-40 \mu \mathrm{M}$ & $\begin{array}{l}\text { Invitrogen (Carlsbad, } \\
\text { CA, USA) }\end{array}$ & ND & Y & $12-48 h$ & $\begin{array}{l}\downarrow \text { Cell proliferation, } \\
\downarrow \text { FAK/cyclin D1 } \\
\text { pathway, } \\
\text { } \text { apoptosis, } \text { cell } \\
\text { invasion, } \\
\downarrow \text { metastasis, } \\
\downarrow \text { migration, } \downarrow \text { FAK } \\
\text { MMPs pathway, } \\
\downarrow \text { kinase activity } \\
\text { of FAK }\end{array}$ & Li et al. (2017) \\
\hline Brain & $\begin{array}{l}\text { U373 and } \\
\text { U87 cell } \\
\text { lines }\end{array}$ & $5-100 \mu \mathrm{M}$ & $\begin{array}{l}\text { Sigma-Aldrich (Lyon, } \\
\text { France) }\end{array}$ & ND & Y & $12-24 \mathrm{~h}$ & $\begin{array}{l}\downarrow \text { Cell growth, } \downarrow \text { cell } \\
\text { viability, } \downarrow \text { migration, } \\
\text { \cell invasion, } \\
\downarrow \text { MMP-9, } \text { MMP-2, } \\
\uparrow M A P K \text { signaling } \\
\text { pathways, } \\
\downarrow \text { metastasis }\end{array}$ & Aroui et al. (2016a) \\
\hline Brain & U251 cell line & $5-60 \mu \mathrm{M}$ & $\begin{array}{l}\text { Sigma-Aldrich (Lyon, } \\
\text { France) }\end{array}$ & (98\%) & Y & $24 \mathrm{~h}$ & $\begin{array}{l}\downarrow \text { Cell proliferation, } \downarrow \text { cell } \\
\text { viability, } \downarrow \text { cell invasion, } \\
\downarrow \text { migration, } \downarrow \text { MMP-9, } \\
\downarrow \text { MMP-2, } \uparrow T I M P-2, \\
\uparrow T I M P-1, \downarrow \text { p38 signal } \\
\text { transduction } \\
\text { pathways }\end{array}$ & $\begin{array}{l}\text { Aroui et al. } \\
\text { (2016b) }\end{array}$ \\
\hline
\end{tabular}


TABLE 3 | (Continued) Potential anticancer effects and related mechanisms of action of naringin based on in vitro studies.

\begin{tabular}{|c|c|c|c|c|c|c|c|c|}
\hline $\begin{array}{l}\text { Cancer } \\
\text { type }\end{array}$ & $\begin{array}{l}\text { Cell } \\
\text { type }\end{array}$ & Conc & Source & $\begin{array}{l}\text { Purity } \\
\text { (\%) }\end{array}$ & $\begin{array}{l}\text { Quality } \\
\text { control } \\
\text { reported? } \\
\text { (Y/N) }\end{array}$ & Duration & $\begin{array}{c}\text { Anticancer } \\
\text { effects }\end{array}$ & References \\
\hline Brain (Glioma) & $\begin{array}{l}\text { U343 and } \\
\text { U118 cell } \\
\text { lines }\end{array}$ & $0.1-100 \mu \mathrm{M}$ & $\begin{array}{l}\text { Sigma-Aldrich } \\
\text { (Steinheim, Germany) }\end{array}$ & ND & Y & $24 \mathrm{~h}$ & $\downarrow$ VEGF & $\begin{array}{l}\text { Schindler and } \\
\text { Mentlein (2006) }\end{array}$ \\
\hline Breast & $\begin{array}{l}\text { MCF-7 cell } \\
\text { line }\end{array}$ & 50-400 $\mu \mathrm{g} / \mathrm{ml}$ & $\begin{array}{l}\text { Sigma-Aldrich (Berlin, } \\
\text { Germany) }\end{array}$ & ND & Y-HPLC & $48-72$ h & $\begin{array}{l}\downarrow \text { Cell proliferation, } \\
\downarrow \text { cell growth, } \\
\text { †apoptosis }\end{array}$ & $\begin{array}{l}\text { Elansary et al. } \\
(2020)\end{array}$ \\
\hline Breast & $\begin{array}{l}\text { MCF7 cell } \\
\text { line }\end{array}$ & $5 \mu \mathrm{M}$ & $\begin{array}{l}\text { Sigma-Aldrich } \\
\text { (St. Louis, MO, USA) }\end{array}$ & ND & Y-HPLC & $12-48$ h & $\begin{array}{l}\downarrow \text { Cell proliferation, } \\
\downarrow \text { cell viability }\end{array}$ & $\begin{array}{l}\text { Puranik et al. } \\
\text { (2019) }\end{array}$ \\
\hline Breast & $\begin{array}{l}\text { MCF7 and } \\
\text { HCT116 cell } \\
\text { lines }\end{array}$ & $0.78-100 \mu \mathrm{g} / \mathrm{ml}$ & $\begin{array}{l}\text { Purified by Basta } \\
\text { et al., } 2020\end{array}$ & ND & Y-TLC & $48 \mathrm{~h}$ & $\begin{array}{l}\downarrow \text { Cell proliferation, } \\
\downarrow \text { cell viability }\end{array}$ & Basta et al. (2020) \\
\hline Breast & $\begin{array}{l}\text { MCF7 cell } \\
\text { line }\end{array}$ & $0.78-100 \mu \mathrm{g} / \mathrm{ml}$ & $\begin{array}{l}\text { Purified by Atta et al., } \\
2019\end{array}$ & ND & Y-TLC & $48 \mathrm{~h}$ & $\begin{array}{l}\downarrow \text { Cell viability, } \downarrow \text { cell } \\
\text { growth, } \uparrow a p o p t o s i s\end{array}$ & Atta et al. (2019) \\
\hline Breast & $\begin{array}{l}\text { MCF-7 cell } \\
\text { line }\end{array}$ & $200 \mu \mathrm{M}$ & $\begin{array}{l}\text { Sigma-Aldrich } \\
\text { (St. Louis, MO, } \\
\text { United States) }\end{array}$ & $(\geq 95 \%)$ & Y & $72 \mathrm{~h}$ & $\begin{array}{l}\downarrow \text { Cell proliferation, } \\
\downarrow \text { cell viability, } \\
\text { †apoptosis }\end{array}$ & $\begin{array}{l}\text { Fazary et al. } \\
(2017)\end{array}$ \\
\hline Breast & $\begin{array}{l}\text { MCF7 cell } \\
\text { line }\end{array}$ & $0.3-5 \mu \mathrm{M}$ & $\begin{array}{l}\text { Merck Chemical Co. } \\
\text { (Darmstadt, Germany) }\end{array}$ & ND & Y & $24-48 \mathrm{~h}$ & $\begin{array}{l}\downarrow \text { Cell proliferation, } \\
\downarrow \text { cell viability }\end{array}$ & $\begin{array}{l}\text { Karami et al. } \\
(2018)\end{array}$ \\
\hline Breast & $\begin{array}{l}\text { MCF7 cell } \\
\text { line }\end{array}$ & $20-100 \mu \mathrm{M}$ & $\begin{array}{l}\text { Sigma-Aldrich } \\
\text { (St. Louis, MO, USA) }\end{array}$ & (97\%) & Y-HPLC & $1-48 h$ & $\begin{array}{l}\downarrow \text { Cell proliferation, } \\
\downarrow \text { cell viability }\end{array}$ & $\begin{array}{l}\text { Selvaraj et al. } \\
(2014)\end{array}$ \\
\hline Breast & $\begin{array}{l}\text { MCF-7 and } \\
\text { MDA-MB- } \\
231 \text { cell lines }\end{array}$ & $5-100 \mu \mathrm{M}$ & $\begin{array}{l}\text { Sigma-Aldrich } \\
\text { (Poznań, Poland) }\end{array}$ & ND & Y & $24-48 \mathrm{~h}$ & $\begin{array}{l}\downarrow \text { Cell viability, } \uparrow \text { cell } \\
\text { cycle arrest, } \\
\uparrow \text { apoptosis }\end{array}$ & $\begin{array}{l}\text { Kabała-Dzik et al. } \\
(2018)\end{array}$ \\
\hline Breast & $\begin{array}{l}\text { CMT-U27 } \\
\text { cell line }\end{array}$ & $20-1,000 \mu \mathrm{M}$ & $\begin{array}{l}\text { Sigma-Aldrich } \\
\text { Chemical Co. } \\
\text { (Steinheim, Germany) }\end{array}$ & ND & Y & $48 \mathrm{~h}$ & $\begin{array}{l}\downarrow \text { Cell proliferation, } \\
\downarrow \text { cell viability }\end{array}$ & $\begin{array}{l}\text { Özyürek et al. } \\
\text { (2014) }\end{array}$ \\
\hline Breast & $\begin{array}{l}\text { MDA-MB- } \\
231, \text { MDA- } \\
\text { MB-468, } \\
\text { and BT-549 } \\
\text { cell lines }\end{array}$ & 50-200 $\mu \mathrm{M}$ & $\begin{array}{l}\text { Sigma-Aldrich } \\
\text { (St. Louis, MO, USA) }\end{array}$ & $(\geq 95 \%)$ & Y-HPLC & $24-48$ h & $\begin{array}{l}\downarrow \text { Cell proliferation, } \\
\downarrow \text { cell growth, } \uparrow \text { cell } \\
\text { cycle arrest, } \downarrow \text { cell } \\
\text { viability, } \uparrow \text { apoptosis, } \\
\downarrow \boldsymbol{\beta} \text {-catenin pathway }\end{array}$ & Li et al. (2013a) \\
\hline Breast & $\begin{array}{l}\text { Ehrlich } \\
\text { ascites } \\
\text { tumor cells }\end{array}$ & $5-100 \mu \mathrm{M}$ & $\begin{array}{l}\text { Sigma-Aldrich } \\
\text { (St. Louis, MO, USA) }\end{array}$ & ND & Y & $3-24 \mathrm{~h}$ & $\begin{array}{l}\uparrow \text { Tumor cell death, } \\
\downarrow \text { tumor cell growth }\end{array}$ & $\begin{array}{l}\text { Menon et al. } \\
(1995)\end{array}$ \\
\hline Breast & $\begin{array}{l}\text { MDA-MB- } \\
231 \text { cell line }\end{array}$ & $0.1-100 \mu \mathrm{M}$ & $\begin{array}{l}\text { Sigma-Aldrich } \\
\text { (St. Louis, MO, USA) }\end{array}$ & ND & Y & $24 \mathrm{~h}$ & $\downarrow$ VEGF & $\begin{array}{l}\text { Schindler and } \\
\text { Mentlein (2006) }\end{array}$ \\
\hline Cervical & $\begin{array}{l}\text { C33A, SiHa, } \\
\text { and HeLa } \\
\text { cell lines }\end{array}$ & $10-10,000 \mu \mathrm{M}$ & $\begin{array}{l}\text { Sigma-Aldrich } \\
\text { (St. Louis, MO, USA) }\end{array}$ & $(\geq 95 \%)$ & Y-HPLC & $24 \mathrm{~h}$ & $\begin{array}{l}\downarrow \text { Cell viability, } \uparrow \text { cell } \\
\text { cycle arrest, } \\
\uparrow \text { apoptosis, \Wnt/ } \\
\boldsymbol{\beta} \text {-catenin pathway }\end{array}$ & Chen et al. (2020) \\
\hline Cervical & SiHa cell line & 250-2000 $\mu \mathrm{M}$ & $\begin{array}{l}\text { Sigma-Aldrich } \\
\text { (St. Louis, MO, } \\
\text { United States) }\end{array}$ & ND & Y & $24-48 \mathrm{~h}$ & $\begin{array}{l}\downarrow \text { Cell proliferation, } \\
\downarrow \text { cell viability, } \uparrow \text { cell } \\
\text { cycle arrest, } \\
\uparrow \text { apoptosis, } \\
\uparrow \text { caspases, } \uparrow p 53, \\
\uparrow \text { Bax, } \uparrow F a s\end{array}$ & $\begin{array}{l}\text { Ramesh and } \\
\text { Alshatwi (2013) }\end{array}$ \\
\hline Cervical & HeLa cell line & 200-2000 $\mu \mathrm{M}$ & $\begin{array}{l}\text { Sigma-Aldrich } \\
\text { (St. Louis, MO, } \\
\text { United States) }\end{array}$ & ND & Y & $24 \mathrm{~h}$ & $\begin{array}{l}\downarrow \text { Cell proliferation, } \\
\downarrow \text { cell growth, } \\
\text { †apoptosis }\end{array}$ & Liu et al. (2017) \\
\hline Cervical & HeLa cell line & 200-3200 $\mu \mathrm{M}$ & $\begin{array}{l}\text { Nacalai tesque } \\
\text { (Kyoto, Japan) }\end{array}$ & ND & Y & $48 \mathrm{~h}$ & $\begin{array}{l}\downarrow \text { Cell growth, } \\
\text { } \text { apoptosis, } \downarrow N E U 3, \\
\uparrow E G F R / E R K \\
\text { signaling }\end{array}$ & $\begin{array}{l}\text { Yoshinaga et al. } \\
(2016)\end{array}$ \\
\hline Cervical & HeLa cell line & $10-1,000 \mu \mathrm{M}$ & $\begin{array}{l}\text { Extrasynthese-Genay } \\
\text { (Lyon, France) }\end{array}$ & ND & Y & $24 \mathrm{~h}$ & $\begin{array}{l}\downarrow \text { Cell proliferation, } \\
\downarrow \text { cell growth }\end{array}$ & $\begin{array}{l}\text { Ramanathan et al. } \\
\text { (1992) }\end{array}$ \\
\hline Cervical & HeLa cell line & $50-400 \mu \mathrm{g} / \mathrm{ml}$ & $\begin{array}{l}\text { Sigma-Aldrich (Berlin, } \\
\text { Germany) }\end{array}$ & ND & Y-HPLC & $48-72$ h & $\begin{array}{l}\downarrow \text { Cell proliferation, } \\
\downarrow \text { cell growth, } \\
\uparrow \text { apoptosis }\end{array}$ & $\begin{array}{l}\text { Elansary et al. } \\
(2020)\end{array}$ \\
\hline Cervical & HeLa cell line & $\begin{array}{c}200-1,500 \mu \mathrm{mol} / \\
\mathrm{L}\end{array}$ & $\begin{array}{l}\text { Sigma-Aldrich } \\
\text { (St. Louis, MO, } \\
\text { United States) }\end{array}$ & ND & Y & $3-48 \mathrm{~h}$ & $\begin{array}{l}\downarrow \text { Cell viability, } \downarrow \text { cell } \\
\text { growth, } \uparrow \text { apoptosis, } \\
\downarrow \text { NF-kB/COX-2- } \\
\text { caspase-1 pathway } \\
\text { (Continued }\end{array}$ & n following page) \\
\hline
\end{tabular}


TABLE 3 | (Continued) Potential anticancer effects and related mechanisms of action of naringin based on in vitro studies.

\begin{tabular}{|c|c|c|c|c|c|c|c|c|}
\hline $\begin{array}{l}\text { Cancer } \\
\text { type }\end{array}$ & $\begin{array}{l}\text { Cell } \\
\text { type }\end{array}$ & Conc & Source & $\begin{array}{c}\text { Purity } \\
\text { (\%) }\end{array}$ & $\begin{array}{l}\text { Quality } \\
\text { control } \\
\text { reported? } \\
\text { (Y/N) }\end{array}$ & Duration & $\begin{array}{c}\text { Anticancer } \\
\text { effects }\end{array}$ & References \\
\hline Colon & $\begin{array}{l}\text { HT-29 cell } \\
\text { line }\end{array}$ & $50-400 \mu \mathrm{g} / \mathrm{ml}$ & $\begin{array}{l}\text { Sigma-Aldrich (Berlin, } \\
\text { Germany) }\end{array}$ & ND & Y-HPLC & $48-72 \mathrm{~h}$ & $\begin{array}{l}\downarrow \text { Cell proliferation, } \\
\downarrow \text { cell growth, } \\
\text { †apoptosis }\end{array}$ & $\begin{array}{l}\text { Elansary et al. } \\
(2020)\end{array}$ \\
\hline Colon & CT26 cell line & $1-100 \mu \mathrm{g} / \mathrm{ml}$ & $\begin{array}{l}\text { Purified by Zhou et al., } \\
2018\end{array}$ & ND & Y- HPLC & & $\begin{array}{l}\downarrow \text { Cell proliferation, } \\
\downarrow \text { cell viability, } \\
\uparrow \text { apoptosis }\end{array}$ & Zhou et al. (2018) \\
\hline Colon & $\begin{array}{l}\text { SW480 cell } \\
\text { line }\end{array}$ & $12.5-200 \mu \mathrm{M}$ & $\begin{array}{l}\text { Sigma-Aldrich } \\
\text { (St. Louis, MO, USA) }\end{array}$ & ND & Y & $12-48 h$ & $\begin{array}{l}\downarrow \text { Cell proliferation, } \\
\downarrow \text { cell viability }\end{array}$ & $\begin{array}{l}\text { Chidambara } \\
\text { Murthy et al. } \\
(2012)\end{array}$ \\
\hline Colorectal & $\begin{array}{l}\text { HCT } 116 \text { and } \\
\text { SW620 cell } \\
\text { lines }\end{array}$ & $6-25 \mu \mathrm{g} / \mathrm{ml}$ & $\begin{array}{l}\text { Beijing Solarbio } \\
\text { Science and } \\
\text { Technology Co., Ltd } \\
\text { (Beijing, China) }\end{array}$ & ND & Y & $12-72 \mathrm{~h}$ & $\begin{array}{l}\downarrow \text { Cell proliferation, } \\
\text { } a p o p t o s i s, ~ \downarrow P I 3 k / \\
\text { Akt/mTOR pathway }\end{array}$ & $\begin{array}{l}\text { Cheng et al. } \\
(2020)\end{array}$ \\
\hline Colon & $\begin{array}{l}\text { Colo } 205 \\
\text { and Colo } \\
320 \text { cell lines }\end{array}$ & $4-10 \mu \mathrm{g} / \mathrm{ml}$ & $\begin{array}{l}\text { Purified by Ugocsai } \\
\text { et al. (2005) }\end{array}$ & ND & Y & $24 \mathrm{~h}$ & $\uparrow$ Apoptosis & $\begin{array}{l}\text { Ugocsai et al. } \\
\text { (2005) }\end{array}$ \\
\hline Colon & $\begin{array}{l}\text { COLO } \\
320 H S R, \\
\text { COLO 205, } \\
\text { and HT 29 } \\
\text { cell lines }\end{array}$ & $200 \mu \mathrm{M}$ & $\begin{array}{l}\text { Sigma-Aldrich } \\
\text { (St. Louis, MO, USA) }\end{array}$ & ND & Y & $24 \mathrm{~h}$ & No effect & Shen et al. (2004) \\
\hline Colon & HT29 cell line & $10-250 \mu \mathrm{g} / \mathrm{ml}$ & $\begin{array}{l}\text { Sigma-Aldrich } \\
\text { (St. Louis, MO, USA) }\end{array}$ & ND & $\begin{array}{l}\text { Y-HPLC and } \\
\text { mass } \\
\text { spectrometer }\end{array}$ & $24-48 h$ & $\begin{array}{l}\downarrow \text { Cell proliferation, } \\
\downarrow \text { cell growth }\end{array}$ & $\begin{array}{l}\text { Ferreira et al. } \\
(2013)\end{array}$ \\
\hline Colon & $\begin{array}{l}\text { HCT116 cell } \\
\text { line }\end{array}$ & $200 \mu \mathrm{M}$ & $\begin{array}{l}\text { Sigma Aldrich } \\
\text { (St. Louis, MO, } \\
\text { United States) }\end{array}$ & $(\geq 95 \%)$ & Y & $72 \mathrm{~h}$ & $\begin{array}{l}\downarrow \text { Cell proliferation, } \\
\downarrow \text { cell viability, } \\
\uparrow \text { apoptosis }\end{array}$ & $\begin{array}{l}\text { Fazary et al. } \\
(2017)\end{array}$ \\
\hline Colon & $\begin{array}{l}\text { HCT116 cell } \\
\text { line }\end{array}$ & $0.78-100 \mu \mathrm{g} / \mathrm{ml}$ & $\begin{array}{l}\text { Purified by Basta } \\
\text { et al., } 2020\end{array}$ & ND & Y-TLC & $48 \mathrm{~h}$ & $\begin{array}{l}\downarrow \text { Cell proliferation, } \\
\downarrow \text { cell viability }\end{array}$ & Basta et al. (2020) \\
\hline Colon & $\begin{array}{l}\text { SNU-C4 cell } \\
\text { line }\end{array}$ & $1-2 \mathrm{mM}$ & $\begin{array}{l}\text { Sigma-Aldrich } \\
\text { (St. Louis, MO, USA) }\end{array}$ & ND & Y & $12 \mathrm{~h}$ & 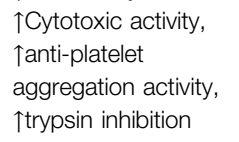 & Kim et al. (1998) \\
\hline Colorectal & $\begin{array}{l}\text { Caco-2 cell } \\
\text { line }\end{array}$ & $10-1,000 \mu \mathrm{M}$ & $\begin{array}{l}\text { Sigma-Aldrich } \\
\text { (St. Louis, MO, USA) }\end{array}$ & ND & Y & $24 \mathrm{~h}$ & $\begin{array}{l}\downarrow \text { Cell proliferation, } \\
\downarrow \text { cell growth, } \downarrow \text { cell } \\
\text { viability } \downarrow \text { GLO-। } \\
\text { activity }\end{array}$ & Yadav et al. (2016) \\
\hline Colon & $\begin{array}{l}\text { HT-29 and } \\
\text { Caco- } 2 \text { cell } \\
\text { lines }\end{array}$ & $10-60 \mu \mathrm{M}$ & $\begin{array}{l}\text { Fluka Chemika- } \\
\text { BioChemika (New } \\
\text { York, USA) }\end{array}$ & $(>95 \%)$ & Y & $24-48 h$ & No effect & Kuo (1996) \\
\hline Esophageal & YM1 cell line & $300 \mu \mathrm{M}$ & $\begin{array}{l}\text { Sigma-Aldrich } \\
\text { (St. Louis, MO, USA) }\end{array}$ & ND & Y & $24 \mathrm{~h}$ & $\begin{array}{l}\downarrow \text { Cell proliferation, } \\
\downarrow \text { cell viability }\end{array}$ & $\begin{array}{l}\text { Tajaldini et al. } \\
(2020)\end{array}$ \\
\hline $\begin{array}{l}\text { Head and Neck } \\
\text { (laryngeal) }\end{array}$ & $\begin{array}{l}\text { HEp2 cell } \\
\text { line }\end{array}$ & $3.8-500 \mu \mathrm{M}$ & $\begin{array}{l}\text { Sigma-Aldrich } \\
\text { (St. Louis, MO, USA) }\end{array}$ & ND & Y & $72 \mathrm{~h}$ & $\begin{array}{l}\downarrow \text { Cell viability, } \downarrow \text { lipid } \\
\text { peroxidation, } \\
\uparrow C Y P 1 A 1\end{array}$ & Durgo et al. (2007) \\
\hline Liver & $\begin{array}{l}\text { HepG2 cell } \\
\text { line }\end{array}$ & $12.5 \mu \mathrm{M}-3.2 \mathrm{mM}$ & $\begin{array}{l}\text { Sigma-Aldrich } \\
\text { (St. Louis, MO, } \\
\text { United States) }\end{array}$ & $(\geq 95 \%)$ & Y-HPLC & $48 \mathrm{~h}$ & $\begin{array}{l}\downarrow \text { Cell viability, } \downarrow \text { cell } \\
\text { growth, } \uparrow \text { apoptosis }\end{array}$ & $\begin{array}{l}\text { Elsawy et al. } \\
(2020)\end{array}$ \\
\hline Liver & $\begin{array}{l}\text { HepG2 cell } \\
\text { line }\end{array}$ & $5 \mu \mathrm{M}$ & $\begin{array}{l}\text { Sigma-Aldrich } \\
\text { (St. Louis, MO, } \\
\text { United States) }\end{array}$ & ND & Y & $24 \mathrm{~h}$ & $\begin{array}{l}\downarrow \text { Cell proliferation, } \\
\downarrow \text { cell viability }\end{array}$ & Syed et al. (2020) \\
\hline Liver & $\begin{array}{l}\text { HepG2 cell } \\
\text { line }\end{array}$ & $10-40 \mu \mathrm{M}$ & $\begin{array}{l}\text { Sigma-Aldrich } \\
\text { (St. Louis, MO, USA) }\end{array}$ & ND & Y & $24-72 \mathrm{~h}$ & $\begin{array}{l}\downarrow \text { Cell proliferation, } \\
\text { †apoptosis, } \uparrow \text { Bax, } \\
\downarrow \text { Bcl-2, } \uparrow \text { miR-19b }\end{array}$ & Xie et al. (2017) \\
\hline Liver & $\begin{array}{l}\text { HepG2 cell } \\
\text { line }\end{array}$ & $50-250 \mu \mathrm{g} / \mathrm{ml}$ & $\begin{array}{l}\text { Sigma-Aldrich } \\
\text { (St. Louis, MO, } \\
\text { United States) }\end{array}$ & ND & Y & $24 \mathrm{~h}$ & $\begin{array}{l}\downarrow \text { Cell proliferation, } \\
\downarrow \text { cell viability, } \downarrow \text { cell } \\
\text { growth, } \uparrow \text { apoptosis }\end{array}$ & $\begin{array}{l}\text { Banjerdpongchai } \\
\text { et al. (2016a) }\end{array}$ \\
\hline Liver & $\begin{array}{l}\text { HepG2 cell } \\
\text { line }\end{array}$ & $100 \mu \mathrm{g} / \mathrm{ml}$ & $\begin{array}{l}\text { Sigma-Aldrich } \\
\text { (St. Louis, MO, } \\
\text { United States) }\end{array}$ & ND & Y & $24 \mathrm{~h}$ & $\begin{array}{l}\downarrow \text { Cell proliferation, } \\
\uparrow a p o p t o s i s, ~ \uparrow B a x, \\
\uparrow B a k, \downarrow B c l-x L, \uparrow t B i d \\
\text { (Continued }\end{array}$ & $\begin{array}{l}\text { Banjerdpongchai } \\
\text { et al. (2016b) } \\
\text { n following page) }\end{array}$ \\
\hline
\end{tabular}


TABLE 3 | (Continued) Potential anticancer effects and related mechanisms of action of naringin based on in vitro studies.

\begin{tabular}{|c|c|c|c|c|c|c|c|c|}
\hline $\begin{array}{l}\text { Cancer } \\
\text { type }\end{array}$ & $\begin{array}{l}\text { Cell } \\
\text { type }\end{array}$ & Conc & Source & $\begin{array}{c}\text { Purity } \\
\text { (\%) }\end{array}$ & $\begin{array}{l}\text { Quality } \\
\text { control } \\
\text { reported? } \\
\text { (Y/N) }\end{array}$ & Duration & $\begin{array}{c}\text { Anticancer } \\
\text { effects }\end{array}$ & References \\
\hline Liver & $\begin{array}{l}\text { HepG2 cell } \\
\text { line }\end{array}$ & $1-100 \mu \mathrm{g} / \mathrm{ml}$ & $\begin{array}{l}\text { Purified by Zhou et al., } \\
2018\end{array}$ & ND & Y- HPLC & & $\begin{array}{l}\downarrow \text { Cell proliferation, } \\
\downarrow \text { cell viability, } \\
\uparrow \text { apoptosis }\end{array}$ & Zhou et al. (2018) \\
\hline Liver & $\begin{array}{l}\text { HepG2, } \\
\text { Huh-7, and } \\
\text { HA22T cell } \\
\text { lines }\end{array}$ & $25-100 \mu \mathrm{M}$ & $\begin{array}{l}\text { Sigma-Aldrich } \\
\text { (St. Louis, MO, } \\
\text { United States) }\end{array}$ & $(>98 \%)$ & Y & $8-24 h$ & $\begin{array}{l}\downarrow \text { Cell invasion, } \\
\downarrow \text { migration, } \\
\downarrow \text { metastasis, } \text { MMP- } \\
9, \downarrow P I 3 K / A k t, \\
\downarrow M A P K, \downarrow \text { I B }\end{array}$ & Yen et al. (2015) \\
\hline Liver & $\begin{array}{l}\text { HepG2 cell } \\
\text { line }\end{array}$ & $10-250 \mu \mathrm{g} / \mathrm{ml}$ & $\begin{array}{l}\text { Sigma-Aldrich } \\
\text { (St. Louis, MO, USA) }\end{array}$ & ND & $\begin{array}{l}\text { Y-HPLC and } \\
\text { mass } \\
\text { spectrometer }\end{array}$ & $24-48 \mathrm{~h}$ & $\begin{array}{l}\downarrow \text { Cell proliferation, } \\
\downarrow \text { cell growth }\end{array}$ & $\begin{array}{l}\text { Ferreira et al. } \\
(2013)\end{array}$ \\
\hline Liver & $\begin{array}{l}\text { HepG2, } \\
\text { MCF-7, and } \\
\text { HCT116 cell } \\
\text { lines }\end{array}$ & 200 mM & $\begin{array}{l}\text { Sigma-Aldrich } \\
\text { (St. Louis, MO, } \\
\text { United States) }\end{array}$ & $(\geq 95 \%)$ & $Y$ & $72 \mathrm{~h}$ & $\begin{array}{l}\downarrow \text { Cell proliferation, } \\
\downarrow \text { cell viability, } \\
\uparrow a p o p t o s i s\end{array}$ & $\begin{array}{l}\text { Fazary et al. } \\
(2017)\end{array}$ \\
\hline Liver & $\begin{array}{l}\text { HA22T and } \\
\text { SK-Hep1 } \\
\text { cell lines }\end{array}$ & $10-100 \mu \mathrm{M}$ & $\begin{array}{l}\text { Aldrich chem. Co. } \\
\text { (Milwaukee, WI, } \\
\text { United States) }\end{array}$ & ND & Y & $24 \mathrm{~h}$ & $\begin{array}{l}\downarrow \text { Cell viability, } \downarrow \text { cell } \\
\text { growth }\end{array}$ & $\begin{array}{l}\text { Hsiao et al. } \\
\text { (2007a) }\end{array}$ \\
\hline Liver & $\begin{array}{l}\text { HepG2 cell } \\
\text { line }\end{array}$ & $1-2 \mathrm{mM}$ & $\begin{array}{l}\text { Sigma-Aldrich } \\
\text { (St. Louis, MO, USA) }\end{array}$ & ND & Y & $12 \mathrm{~h}$ & 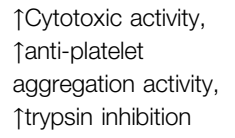 & Kim et al. (1998) \\
\hline Liver & $\begin{array}{l}\text { Hepa-1c1c7 } \\
\text { cell line }\end{array}$ & 50-100 $\mu \mathrm{M}$ & $\begin{array}{l}\text { Sigma-Aldrich } \\
\text { (St. Louis, MO, USA) }\end{array}$ & ND & Y & $72 \mathrm{~h}$ & No effect & $\begin{array}{l}\text { Campbell et al. } \\
\text { (2006) }\end{array}$ \\
\hline Lung & A549 cell line & $3-1,000 \mu \mathrm{M}$ & $\begin{array}{l}\text { Purified by Nie et al., } \\
2012\end{array}$ & (>98.3\%) & $\begin{array}{c}\text { Y-determined by } \\
\text { peak area } \\
\text { normalization }\end{array}$ & 24-96 h & $\begin{array}{l}\downarrow \text { Cell proliferation, } \\
\downarrow \text { cell viability }\end{array}$ & Nie et al. (2012) \\
\hline Lung & $\begin{array}{l}\text { A549 and } \\
\text { LLC cell lines }\end{array}$ & $10-100 \mu \mathrm{M}$ & $\begin{array}{l}\text { Aldrich chem. Co. } \\
\text { (Milwaukee, WI, } \\
\text { United States) }\end{array}$ & ND & Y & $24 \mathrm{~h}$ & $\begin{array}{l}\downarrow \text { Cell viability, } \downarrow \text { cell } \\
\text { growth }\end{array}$ & $\begin{array}{l}\text { Hsiao et al. } \\
\text { (2007a) }\end{array}$ \\
\hline Lung & $\begin{array}{l}\text { H69AR cell } \\
\text { line }\end{array}$ & $6-25 \mu \mathrm{g} / \mathrm{ml}$ & ND & ND & ND & $24 \mathrm{~h}$ & 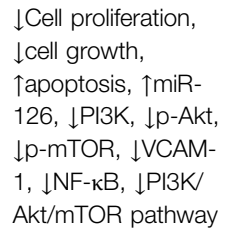 & Chen et al. (2018) \\
\hline Lung & A549 cell line & $10-50 \mu \mathrm{M}$ & $\begin{array}{l}\text { Aldrich chem. Co. } \\
\text { (Milwaukee, WI, } \\
\text { United States) }\end{array}$ & ND & Y & $24 \mathrm{~h}$ & $\begin{array}{l}\downarrow \text { Cell viability, } \downarrow \text { cell } \\
\text { invasion, } \downarrow \text { cell- } \\
\text { matrix adhesion, } \\
\downarrow \text { cellular motility }\end{array}$ & $\begin{array}{l}\text { Hsiao et al. } \\
\text { (2007b) }\end{array}$ \\
\hline Lung & A549 cell line & $1-2 \mathrm{mM}$ & $\begin{array}{l}\text { Sigma-Aldrich } \\
\text { (St. Louis, MO, USA) }\end{array}$ & ND & Y & $12 \mathrm{~h}$ & 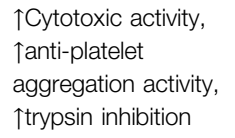 & Kim et al. (1998) \\
\hline Lung & A549 cell line & $10-120 \mu \mathrm{g} / \mathrm{ml}$ & $\begin{array}{l}\text { Sigma-Aldrich, } \\
\text { (St. Louis, MO, } \\
\text { United States) }\end{array}$ & ND & Y & $6-24 \mathrm{~h}$ & $\begin{array}{l}\downarrow \text { Cell proliferation, } \\
\downarrow \text { cell viability, } \\
\uparrow \text { apoptosis }\end{array}$ & $\begin{array}{l}\text { Garcia et al. } \\
(2019)\end{array}$ \\
\hline Lung & A549 cell line & $0.78-100 \mu \mathrm{g} / \mathrm{ml}$ & $\begin{array}{l}\text { Purified by Atta et al., } \\
2019\end{array}$ & ND & Y-TLC & $48 \mathrm{~h}$ & $\begin{array}{l}\downarrow \text { Cell viability, } \downarrow \text { cell } \\
\text { growth, } \uparrow a p o p t o s i s\end{array}$ & Atta et al. (2019) \\
\hline Lung & $\begin{array}{l}\text { HeLa and } \\
\text { A549 cell } \\
\text { lines }\end{array}$ & $200-3200 \mu \mathrm{M}$ & $\begin{array}{l}\text { Nacalai Tesque, Inc. } \\
\text { (Kyoto, Japan) }\end{array}$ & ND & Y & $48 \mathrm{~h}$ & $\begin{array}{l}\downarrow \text { Cell growth, } \\
\text { } a \text { apoptosis, } \downarrow \text { NEU3, } \\
\uparrow E G F R / E R K \\
\text { signaling }\end{array}$ & $\begin{array}{l}\text { Yoshinaga et al. } \\
(2016)\end{array}$ \\
\hline Neuroblastoma & $\begin{array}{l}\text { SH-SY5Y } \\
\text { cell line }\end{array}$ & $1-10 \mu \mathrm{M}$ & $\begin{array}{l}\text { Sigma-Aldrich } \\
\text { (St. Louis, MO, USA) }\end{array}$ & ND & Y & $24 \mathrm{~h}$ & $\begin{array}{l}\downarrow \text { Cell viability, } \uparrow \text { cell } \\
\text { death }\end{array}$ & Kim et al. (2009) \\
\hline Ovarian & $\begin{array}{l}\text { SKOV3/ } \\
\text { CDDP cell } \\
\text { line }\end{array}$ & $10-40 \mu \mathrm{mol} / \mathrm{L}$ & $\begin{array}{l}\text { Institute of } \\
\text { pharmacology at } \\
\text { Nanchang university } \\
\text { (Nanchang, China) }\end{array}$ & ND & Y & $48 \mathrm{~h}$ & $\downarrow N F-\kappa B, \downarrow P-g p$ & Zhu et al. (2018) \\
\hline
\end{tabular}

Continued on following page) 
TABLE 3 | (Continued) Potential anticancer effects and related mechanisms of action of naringin based on in vitro studies.

\begin{tabular}{|c|c|c|c|c|c|c|c|c|}
\hline $\begin{array}{l}\text { Cancer } \\
\text { type }\end{array}$ & $\begin{array}{l}\text { Cell } \\
\text { type }\end{array}$ & Conc & Source & $\begin{array}{c}\text { Purity } \\
\text { (\%) }\end{array}$ & $\begin{array}{l}\text { Quality } \\
\text { control } \\
\text { reported? } \\
\text { (Y/N) }\end{array}$ & Duration & $\begin{array}{c}\text { Anticancer } \\
\text { effects }\end{array}$ & References \\
\hline Ovarian & $\begin{array}{l}\text { SKOV3/ } \\
\text { CDDP cell } \\
\text { line }\end{array}$ & $10-40 \mu \mathrm{mol} / \mathrm{L}$ & $\begin{array}{l}\text { Shandong Qilu } \\
\text { Pharmaceutical Co., } \\
\text { Ltd. (Shandong, } \\
\text { China) }\end{array}$ & ND & Y & $48 \mathrm{~h}$ & $\downarrow N F-\kappa B, \downarrow C O X-2$ & Zhu et al. (2017) \\
\hline Ovarian & $\begin{array}{l}\text { OVCAR-3 } \\
\text { cell line }\end{array}$ & $5-160 \mu \mathrm{M}$ & $\begin{array}{l}\text { Sigma-Aldrich } \\
\text { (St. Louis, MO, USA) }\end{array}$ & ND & Y & $24 \mathrm{~h}$ & No effect & Luo et al. (2008) \\
\hline Prostate & $\begin{array}{l}\text { PC-3 and } \\
\text { LNCaP cell } \\
\text { lines }\end{array}$ & $2.5-300 \mu \mathrm{M}$ & $\begin{array}{l}\text { Selleck (Maple Valley, } \\
\text { WA, USA) }\end{array}$ & ND & Y & $24-48 \mathrm{~h}$ & $\begin{array}{l}\downarrow \text { Cell growth, } \\
\downarrow \text { migration, } \downarrow \text { cell } \\
\text { invasion, } \\
\uparrow \text { apoptosis, } \uparrow \text { Bax, } \\
\downarrow \text { p- } \downarrow \text { STAT3, } \\
\downarrow \text { survivin, } \downarrow \text { Bcl-2, } \\
\downarrow p \text {-Akt }\end{array}$ & Wu et al. (2019) \\
\hline Prostate & $\begin{array}{l}\text { PC3, } \\
\text { DU145, and } \\
\text { LNCaP cell } \\
\text { lines }\end{array}$ & $3.9-500 \mu \mathrm{M}$ & $\begin{array}{l}\text { Sigma-Aldrich } \\
\text { (St. Louis, MO, } \\
\text { United States) }\end{array}$ & ND & Y & $72 \mathrm{~h}$ & $\begin{array}{l}\downarrow \text { Cell survival, } \downarrow \text { cell } \\
\text { viability, } \uparrow \text { apoptosis, } \\
\uparrow \text { cell cycle arrest, } \\
\uparrow P T E N, \downarrow \text { nuclear } \\
\text { factor-кB p50 } \\
\text { protein, } \downarrow \text { cell } \\
\text { migration, } \downarrow N F-\kappa B \\
\text { signaling }\end{array}$ & $\begin{array}{l}\text { Erdogan et al. } \\
(2018)\end{array}$ \\
\hline Prostate & $\begin{array}{l}\text { DU145 cell } \\
\text { line }\end{array}$ & $50-250 \mu \mathrm{M}$ & $\begin{array}{l}\text { Sigma-Aldrich } \\
\text { (Poznan, Poland) }\end{array}$ & ND & Y & $24 \mathrm{~h}$ & $\begin{array}{l}\downarrow \text { Cell proliferation, } \\
\downarrow \text { cell viability, } \downarrow \text { cell } \\
\text { number, } \uparrow \text { oxidative } \\
\text { stress, } \uparrow \text { apoptosis }\end{array}$ & $\begin{array}{l}\text { Lewinska et al. } \\
\text { (2015) }\end{array}$ \\
\hline $\begin{array}{l}\text { Sarcoma } \\
\text { (osteosarcoma) }\end{array}$ & $\begin{array}{l}\text { MG63 and } \\
\text { U2OS cell } \\
\text { lines }\end{array}$ & 10-20 $\mu \mathrm{mol} / \mathrm{L}$ & $\begin{array}{l}\text { Beyotime } \\
\text { Biotechnology } \\
\text { (Shanghai, China) }\end{array}$ & ND & Y & $24 \mathrm{~h}$ & 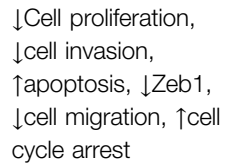 & Ming et al. (2018) \\
\hline $\begin{array}{l}\text { Sarcoma } \\
\text { (osteosarcoma) }\end{array}$ & $\begin{array}{l}\text { MG-63 cell } \\
\text { line }\end{array}$ & $1-100 \mu \mathrm{g} / \mathrm{ml}$ & $\begin{array}{l}\text { Purified by Zhang } \\
\text { et al., } 2018 a\end{array}$ & ND & $\begin{array}{l}\text { Y-HPLC and } \\
\text { Mass } \\
\text { spectrometry }\end{array}$ & 24-72 h & No effect & $\begin{array}{l}\text { Zhang et al. } \\
(2018 \mathrm{a})\end{array}$ \\
\hline $\begin{array}{l}\text { Sarcoma } \\
\text { (chondrosarcoma) }\end{array}$ & $\begin{array}{l}\text { JJ012 cell } \\
\text { line }\end{array}$ & $3-30 \mu \mathrm{M}$ & $\begin{array}{l}\text { Sigma-Aldrich } \\
\text { (St. Louis, MO, } \\
\text { United States) }\end{array}$ & ND & Y & $24-48 \mathrm{~h}$ & $\begin{array}{l}\downarrow \text { Cell invasion, } \\
\downarrow \text { migration, } \downarrow \text { VCAM- } \\
\text { 1, } \uparrow \text { miR-126 }\end{array}$ & Tan et al. (2014) \\
\hline Skin (Melanoma) & $\begin{array}{l}\text { A375 and } \\
\text { A875 cell } \\
\text { lines }\end{array}$ & $10-40 \mu \mathrm{M}$ & ND & ND & ND & $12-60 \mathrm{~h}$ & $\begin{array}{l}\downarrow \text { Cell proliferation, } \\
\downarrow \text { cancer } \\
\text { metabolism, } \uparrow \text { cell } \\
\text { cycle arrest, } \\
\uparrow \text { apoptosis, } \downarrow \text { cell } \\
\text { growth, } \downarrow \text { cell } \\
\text { invasion, } \downarrow \text { migration, } \\
\downarrow \text { c-Src }\end{array}$ & Guo et al. (2016) \\
\hline Skin (Melanoma) & MO4 cell line & $0.5 \mathrm{mM}$ & $\begin{array}{l}\text { Provided by dr. J, A. } \\
\text { Attaway (department } \\
\text { of citrus, state of } \\
\text { Florida, United States) }\end{array}$ & ND & $\begin{array}{l}\text { Y- Reversed- } \\
\text { phase high- } \\
\text { pressure liquid } \\
\text { chromatography }\end{array}$ & 4 days & \lnvasion & $\begin{array}{l}\text { Bracke et al. } \\
(1991)\end{array}$ \\
\hline Skin (Melanoma) & $\begin{array}{l}\text { B16F10 cell } \\
\text { line }\end{array}$ & $5-500 \mu \mathrm{M}$ & $\begin{array}{l}\text { Quinabra Company } \\
\text { (São José dos } \\
\text { Campos, Brazil) }\end{array}$ & ND & Y & 24-72 h & $\begin{array}{l}\downarrow \text { Cell number, } \downarrow \text { cell } \\
\text { growth, } \uparrow \text { cell death, } \\
\downarrow \text { DPPH }\end{array}$ & $\begin{array}{l}\text { Pereira et al. } \\
(2007)\end{array}$ \\
\hline Stomach (Gastric) & AGS cell line & $1-3 \mathrm{mM}$ & $\begin{array}{l}\text { Sigma-Aldrich } \\
\text { (St. Louis, MO, } \\
\text { United States) }\end{array}$ & ND & Y & $3-24 \mathrm{~h}$ & $\begin{array}{l}\text { TROS, } \text { ERK } 1 / 2- \\
\text { p38 MAPKs, } \\
\text { †autophagy cell } \\
\text { death }\end{array}$ & Raha et al. (2020) \\
\hline Stomach (Gastric) & AGS cell line & $10-100 \mu \mathrm{M}$ & $\begin{array}{l}\text { Aldrich Chemical Co. } \\
\text { (Milwakee, WI, } \\
\text { United States) }\end{array}$ & ND & Y & $24 \mathrm{~h}$ & $\begin{array}{l}\downarrow \text { Cell viability, } \downarrow \text { cell } \\
\text { growth }\end{array}$ & $\begin{array}{l}\text { Hsiao et al. } \\
\text { (2007a) }\end{array}$ \\
\hline
\end{tabular}

(Continued on following page) 
TABLE 3 | (Continued) Potential anticancer effects and related mechanisms of action of naringin based on in vitro studies.

\begin{tabular}{|c|c|c|c|c|c|c|c|c|}
\hline $\begin{array}{l}\text { Cancer } \\
\text { type }\end{array}$ & $\begin{array}{l}\text { Cell } \\
\text { type }\end{array}$ & Conc & Source & $\begin{array}{c}\text { Purity } \\
\text { (\%) }\end{array}$ & $\begin{array}{l}\text { Quality } \\
\text { control } \\
\text { reported? } \\
(\mathrm{Y} / \mathrm{N})\end{array}$ & Duration & $\begin{array}{c}\text { Anticancer } \\
\text { effects }\end{array}$ & References \\
\hline Stomach (Gastric) & AGS cell line & $1-3 \mathrm{mM}$ & $\begin{array}{l}\text { Sigma-Aldrich } \\
\text { (St. Louis, MO, } \\
\text { United States) }\end{array}$ & ND & Y & $24-48 \mathrm{~h}$ & $\begin{array}{l}\downarrow \text { Cell proliferation, } \\
\downarrow \text { cell growth, } \downarrow \text { PI3K } \\
\text { Akt/mTOR, } \\
\uparrow M A P K s, \\
\uparrow p 21 \text { CIPINAFI } \\
\text { Tautophagosome }\end{array}$ & Raha et al. (2015) \\
\hline Stomach (Gastric) & SNU-1 & $1-2 \mathrm{mM}$ & $\begin{array}{l}\text { Sigma-Aldrich } \\
\text { (St. Louis, MO, USA) }\end{array}$ & ND & Y & $12 \mathrm{~h}$ & 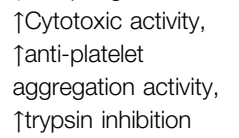 & Kim et al. (1998) \\
\hline Thyroid & $\begin{array}{l}\text { TPC-1 and } \\
\text { SW1736 cell } \\
\text { lines }\end{array}$ & $6-25 \mu \mathrm{g} / \mathrm{ml}$ & $\begin{array}{l}\text { Beyotime } \\
\text { Biotechnology } \\
\text { (Shanghai, China) }\end{array}$ & ND & Y & $24-72 \mathrm{~h}$ & $\begin{array}{l}\downarrow \text { Cell proliferation, } \\
\text { } a p o p t o s i s, ~ \downarrow P I 3 k / \\
\text { Akt pathway }\end{array}$ & Zhou et al. (2019) \\
\hline
\end{tabular}

Note: A down arrow indicates a reduction or decrease and an up arrow indicates an increase. Bak, Bcl-2 homologous antagonist/killer; Bax, Bcl-2-associated X protein; Bcl-2, B-cell lymphoma 2; BCl-xL, B-cell lymphoma-extra-large; COX-2, cyclooxygenase- 2; c-Src, proto-oncogene tyrosine-protein kinase Src; DPPH, diphenylpicrylhydrazyl radical; EGFR, epidermal growth factor receptor; ERK, extracellular signal-regulated kinase; FAK, focal adhesion kinase; GLO-I, glyoxalase-l; I $\mathrm{B}$, inhibitor of NF- $\kappa B$; MMPS, matrix metallopeptidases; MAPK, mitogen-activated protein kinase; Mcl-1, myeloid cell leukemia 1; miR, microRNA; mTOR, mammalian target of rapamycin; ND, not determined; NEU3, plasma membrane-associated sialidase; NF- $\kappa B$, nuclear factor- $\kappa B$; p53, tumor protein p53; $p 38$ MAPKs, p38 mitogen-activated protein kinases; $p$-Akt, phosphorylated Akt; P-gp, P-glycoprotein; PI3K, phosphatidylinositol-3-kinase; p-mTOR, phosphorylated mammalian target of rapamycin; p-STAT3, phosphorylated signal transducer and activator of transcription 3; ROS, reactive oxygen species; tBid, truncated BH3 interacting domain death agonist; TIMP, tissue inhibitor of metalloproteinase; VCAM-1, vascular cell adhesion molecule 1; VEGF, vascular endothelial growth factor; Zeb1, zinc finger E-box binding homeobox 1.

\section{Assessment of Bias and Errors}

The primary search was conducted by two researchers, and they extracted the data independently, which limits the risk of bias and errors.

\section{ANTICANCER ACTIVITIES OF NARINGIN}

Naringin has been shown to inhibit various cancers via different mechanisms, including growth suppression of malignant cells, apoptosis induction and cell cycle arrest, and modulation of oxidative stress, inflammation, and angiogenesis, through the regulation of several cellular signaling cascades. The antitumor effects and associated mechanisms of naringin in various cancers are presented in the following sections.

\section{Bladder Cancer}

Bladder cancer includes a broad range of tumors, including transitional cell carcinoma, which is categorized into three types, namely superficial tumors, tumors confined to the bladder, and invasive tumors. In superficial bladder cancer, the risk of disease recurrence and/or progression to invasive diseases is high (Levi et al., 1993). For these cases, efficient preventive measures are required. One study determined a new mechanism of naringin anticancer activity observed in bladder cancer cell lines. Results demonstrated that naringin treatment suppressed cell viability and growth, and induced $\mathrm{p} 21^{\mathrm{WAF} 1}$ expression and cell cycle arrest in 5,637 and T24 bladder carcinoma cell lines, potentially through suppressing the Ras/Raf/extracellular signalregulated kinase (ERK)-signaling pathway (Table 3) (Kim et al., 2008). Another study showed that treatment with mononuclear palladium (II) complexes of naringin decreased the viability and proliferation of TCC bladder carcinoma cell lines, and these complexes noticeably showed major and selective cytotoxicity toward bladder cancer cells (Karami et al., 2018). In another in vitro study, naringin reduced cell proliferation and viability in TCC Human urinary bladder transitional cell carcinoma cells (Oršolić et al., 2009).

\section{Blood Cancer}

Leukemia is one form of the hematological malignancies with particularly high mortality (Vardiman et al., 2009). At present, leukemia treatment relies on chemotherapies to abrogate malignant cells or to promote differentiation in leukemia cells. Conversely, the available chemotherapies commonly have severe adverse effect (Goldman and Melo, 2003). Accordingly, the discovery of novel therapeutic reagents with a magnificently safe profile is required. One study indicated that treatment of K562, HL-60, and Kasumi-1 human myeloid leukemia cells with naringin blocked cell proliferation and promoted their apoptosis in a time- and concentration-dependent way, via downregulation of Mcl-1 expression and activation of caspase and PARP pathway (Dai et al., 2017). Naringin treatment also enhanced cell death and decreased cell proliferation and growth in U937 (Jin et al., 2009) and THP-1 (Park et al., 2008) human leukemia cells. However, one study showed that naringin had no cytotoxic effect on THP-1 and HL-60 are leukemia cell lines (Chen et al., 2003). In another study, a naringin-derived copper (II) complex 1 was engineered, and its anticancer effect was investigated. Results showed that treatment of K562 human chronic myeloid leukemia cells with naringin-Cu (II) complex 1 or naringin reduced cell proliferation and growth, increased cell death, and decreased diphenylpicrylhydrazyl radical (DPPH). Results also showed that naringin-Cu (II) complex 1 had greater anti-inflammatory, antioxidant, and anticancer activities in comparison to free naringin without decreasing 
TABLE 4 | Potential anticancer effects and related mechanisms of action of naringin based on in vivo studies.

\begin{tabular}{|c|c|c|c|c|c|c|c|c|}
\hline $\begin{array}{l}\text { Cancer } \\
\text { type }\end{array}$ & $\begin{array}{l}\text { Animal } \\
\text { model }\end{array}$ & Dose & Source & $\begin{array}{c}\text { Purity } \\
\text { (\%) }\end{array}$ & $\begin{array}{l}\text { Quality } \\
\text { control } \\
\text { reported? } \\
(\mathrm{Y} / \mathrm{N})\end{array}$ & Duration & $\begin{array}{c}\text { Anticancer } \\
\text { effects }\end{array}$ & References \\
\hline Brain & $\begin{array}{l}\text { Athymic mice } \\
\text { bearing } U-87 \text { tumor }\end{array}$ & $60-180$ mg/kg & $\begin{array}{l}\text { Sigma-Aldrich } \\
\text { (St. Louis, MO, USA) }\end{array}$ & (98\%) & Y & 7 days & $\begin{array}{l}\downarrow \text { Tumor size, } \\
\downarrow \text { survival, } \\
\text { \angiogenesis }\end{array}$ & $\begin{array}{l}\text { Aroui et al. } \\
(2020)\end{array}$ \\
\hline Breast & $\begin{array}{l}\text { SCID female mice } \\
\text { bearing MDA-MB- } \\
231 \text { tumor }\end{array}$ & 100 mg/kg & $\begin{array}{l}\text { Sigma-Aldrich } \\
\text { (St. Louis, MO, USA) }\end{array}$ & $(\geq 95 \%)$ & Y-HPLC & 1-5 weeks & $\begin{array}{l}\downarrow \text { Tumor volume, } \\
\downarrow \text { tumor weight }\end{array}$ & $\begin{array}{l}\text { Li et al. } \\
\text { (2013a) }\end{array}$ \\
\hline Breast & $\begin{array}{l}\text { Swiss albino mice } \\
\text { bearing ehrlich } \\
\text { ascites tumor cells }\end{array}$ & 100 mg/kg & $\begin{array}{l}\text { Sigma-Aldrich Chemie } \\
\text { GmbH (Munich, } \\
\text { Germany) }\end{array}$ & ND & Y & 90 days & $\begin{array}{l}\uparrow \text { Survival, } \downarrow \text { tumor } \\
\text { growth, } \downarrow \text { tumor cell } \\
\text { proliferation, } \uparrow \text { tumor } \\
\text { regression }\end{array}$ & $\begin{array}{l}\text { Benkovic } \\
\text { et al. (2007) }\end{array}$ \\
\hline Breast & $\begin{array}{l}\text { Swiss albino mice } \\
\text { bearing ehrlich } \\
\text { ascites tumor cells }\end{array}$ & 100 mg/kg & $\begin{array}{l}\text { Sigma-Aldrich chemie } \\
\text { GmbH (Germany) }\end{array}$ & ND & Y & 5 days & $\begin{array}{l}\downarrow \text { Tumor growth, } \\
\uparrow \text { survival, } \downarrow \text { tumor } \\
\text { cell proliferation }\end{array}$ & $\begin{array}{l}\text { Oršolić et al. } \\
(2010)\end{array}$ \\
\hline Breast & $\begin{array}{l}\text { Swiss albino mice } \\
\text { bearing ehrlich } \\
\text { ascites tumor cells }\end{array}$ & 100 mg/kg & $\begin{array}{l}\text { Sigma-Aldrich chemie } \\
\text { GmbH (Munich, } \\
\text { Germany) }\end{array}$ & ND & Y & 5 days & $\begin{array}{l}\downarrow \text { Tumor growth, } \\
\uparrow \text { survival, } \downarrow \text { tumor } \\
\text { cell proliferation }\end{array}$ & $\begin{array}{l}\text { Knežević } \\
\text { et al. (2011) }\end{array}$ \\
\hline Breast & $\begin{array}{l}\text { Female Sprague- } \\
\text { dawley rats with } \\
\text { DMBA-induced } \\
\text { breast tumors }\end{array}$ & $\begin{array}{c}500 \mathrm{mg} / 100 \mathrm{~g} \\
\text { diet }\end{array}$ & $\begin{array}{l}\text { Provided by dr. W. } \\
\text { Widmer (state of } \\
\text { Florida dept. of citrus, } \\
\text { United States) }\end{array}$ & ND & $\mathrm{N}$ & 10 weeks & $\begin{array}{l}\downarrow \text { Tumor } \\
\text { development, } \\
\downarrow \text { tumor weight }\end{array}$ & $\begin{array}{l}\text { So et al. } \\
(1996)\end{array}$ \\
\hline Cervix & $\begin{array}{l}\text { Female athymic } \\
\text { nude mice bearing } \\
\text { HeLa tumors }\end{array}$ & $20 \mathrm{mg} / \mathrm{kg}$ & $\begin{array}{l}\text { Sigma-Aldrich } \\
\text { (St. Louis, MO, } \\
\text { United States) }\end{array}$ & ND & Y & 20 days & $\begin{array}{l}\downarrow \text { Tumor growth, } \\
\text { †apoptosis }\end{array}$ & $\begin{array}{l}\text { Liu et al. } \\
(2017)\end{array}$ \\
\hline Colon & $\begin{array}{l}\text { Male C57BL/6 mice } \\
\text { with AOM/DSS- } \\
\text { induced colon } \\
\text { carcinogenesis }\end{array}$ & 50-100 mg/kg & $\begin{array}{l}\text { Sigma-Aldrich } \\
\text { (St. Louis, MO, USA) }\end{array}$ & $(\geq 98 \%)$ & Y & 1-63 days & 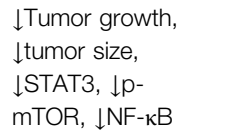 & $\begin{array}{l}\text { Zhang et al. } \\
\text { (2018b) }\end{array}$ \\
\hline Colon & $\begin{array}{l}\text { Male } \\
\text { Sprague-Dawley } \\
\text { rats with AOM- } \\
\text { induced colon } \\
\text { carcinogenesis }\end{array}$ & $200 \mathrm{mg} / \mathrm{kg}$ & $\begin{array}{l}\text { Purified by Vanamala } \\
\text { et al., } 2006\end{array}$ & ND & $\begin{array}{l}\text { Y-Reverse phase } \\
\text { liquid } \\
\text { chromatography }\end{array}$ & 10 weeks & $\begin{array}{l}\downarrow \text { Tumor cell } \\
\text { proliferation, } \\
\uparrow \text { apoptosis }\end{array}$ & $\begin{array}{l}\text { Vanamala } \\
\text { et al. (2006) }\end{array}$ \\
\hline Esophagus & $\begin{array}{l}\text { Male nude mice with } \\
\text { YM1 xenograft } \\
\text { tumors }\end{array}$ & $50 \mathrm{mg} / \mathrm{kg}$ & $\begin{array}{l}\text { Sigma-Aldrich } \\
\text { (St. Louis, MO, USA) }\end{array}$ & ND & Y & 14 days & $\begin{array}{l}\downarrow \text { Tumor size, } \\
\downarrow \text { tumor growth }\end{array}$ & $\begin{array}{l}\text { Tajaldini et al. } \\
(2020)\end{array}$ \\
\hline $\begin{array}{l}\text { Head and neck } \\
\text { (oral cavity) }\end{array}$ & $\begin{array}{l}\text { Hamster cheek } \\
\text { pouch oral cancer } \\
\text { model }\end{array}$ & $0.5-8.0 \mathrm{mg} / \mathrm{kg}$ & ND & ND & ND & & $\begin{array}{l}\downarrow \text { Tumor growth, } \\
\text { \tumor number, } \\
\text { \tumor burden }\end{array}$ & $\begin{array}{l}\text { Miller et al. } \\
(2008)\end{array}$ \\
\hline Liver & $\begin{array}{l}\text { Male Wistar rats } \\
\text { bearing DEN- } \\
\text { induced } \\
\text { hepatocellular } \\
\text { carcinoma }\end{array}$ & $40 \mathrm{mg} / \mathrm{kg}$ & $\begin{array}{l}\text { Sigma-Aldrich } \\
\text { (St. Louis, MO, USA) }\end{array}$ & ND & Y & 6-16 weeks & $\begin{array}{l}\downarrow \text { Cell proliferation, } \\
\text { } a \text { apoptosis, } \\
\downarrow \text { AgNOR/nuclei }\end{array}$ & $\begin{array}{l}\text { Thangavel } \\
\text { and Vaiyapuri } \\
\text { (2013) }\end{array}$ \\
\hline Ovary & $\begin{array}{l}\text { Female BALB/c } \\
\text { nude mice bearing } \\
\text { SKOV3 tumor }\end{array}$ & $0.5-2 \mathrm{mg} / \mathrm{kg}$ & $\begin{array}{l}\text { Merck KGaA } \\
\text { (Darmstadt, Germany) }\end{array}$ & (>90\%) & Y & 10 days & $\begin{array}{l}\uparrow \text { Apoptosis, } \downarrow \text { tumor } \\
\text { size, } \downarrow \text { tumor weight, } \\
\downarrow \text { tumor growth, } \\
\downarrow \text { Bcl-xL, } \text { Bcl-2, } \\
\downarrow \text { cyclin D1, } \downarrow \text { c-Myc, } \\
\downarrow \text { survivin, } \\
\uparrow \text { caspase-3, } \\
\uparrow \text { caspase-7 }\end{array}$ & $\begin{array}{l}\text { Cai et al. } \\
(2018)\end{array}$ \\
\hline Prostate & $\begin{array}{l}\text { Male SCID mice } \\
\text { bearing PC-3 and } \\
\text { LNCaP tumors }\end{array}$ & $50 \mathrm{mg} / \mathrm{kg}$ & $\begin{array}{l}\text { Selleck (Maple Valley, } \\
\text { WA, USA) }\end{array}$ & ND & Y & 16 days & $\begin{array}{l}\downarrow \text { Tumors growth, } \\
\text { †apoptosis }\end{array}$ & $\begin{array}{l}\text { Wu et al. } \\
(2019)\end{array}$ \\
\hline $\begin{array}{l}\text { Sarcoma } \\
\text { (osteosarcoma) }\end{array}$ & $\begin{array}{l}\text { Female, athymic } \\
\text { nude BALB/c mice } \\
\text { bearing MG63 } \\
\text { tumor }\end{array}$ & 5-10 mg/kg & $\begin{array}{l}\text { Beyotime } \\
\text { Biotechnology } \\
\text { (Shanghai, China) }\end{array}$ & ND & $\mathrm{Y}$ & 16 days & $\begin{array}{l}\downarrow \text { Invasion, } \\
\downarrow \text { migration } \downarrow \text { cyclin } \\
\text { D1, } \text { MMP-2, } \\
\downarrow \text { Bcl-2, } \downarrow \text { Zeb1 }\end{array}$ & $\begin{array}{l}\text { Ming et al. } \\
\text { (2018) }\end{array}$ \\
\hline Sarcoma & $\begin{array}{l}\text { Male ddY mice } \\
\text { bearing S180 tumor }\end{array}$ & $30-300$ mg/kg & $\begin{array}{l}\text { Sigma-Aldrich } \\
\text { (St. Louis, MO, USA) }\end{array}$ & ND & Y & 5 days & $\downarrow$ Tumor growth & $\begin{array}{l}\text { Kanno et al. } \\
(2005)\end{array}$ \\
\hline
\end{tabular}


TABLE 4 | (Continued) Potential anticancer effects and related mechanisms of action of naringin based on in vivo studies.

\begin{tabular}{|c|c|c|c|c|c|c|c|c|}
\hline $\begin{array}{l}\text { Cancer } \\
\text { type }\end{array}$ & $\begin{array}{l}\text { Animal } \\
\text { model }\end{array}$ & Dose & Source & $\begin{array}{c}\text { Purity } \\
(\%)\end{array}$ & $\begin{array}{l}\text { Quality } \\
\text { control } \\
\text { reported? } \\
\text { (Y/N) }\end{array}$ & Duration & $\begin{array}{c}\text { Anticancer } \\
\text { effects }\end{array}$ & References \\
\hline $\begin{array}{l}\text { Sarcoma } \\
\text { (carcinosarcoma) }\end{array}$ & $\begin{array}{l}\text { Male Wistar rats } \\
\text { bearing W256 tumor }\end{array}$ & $10-35 \mathrm{mg} / \mathrm{kg}$ & $\begin{array}{l}\text { Sigma-Aldrich } \\
\text { (St. Louis, MO, USA) }\end{array}$ & ND & Y & 50 days & $\begin{array}{l}\downarrow \text { Tumor growth, } \\
\uparrow \text { survival, } \downarrow \text { TNF- } \alpha \text {, } \\
\downarrow \text { IL-6 }\end{array}$ & $\begin{array}{l}\text { Camargo } \\
\text { et al. (2012) }\end{array}$ \\
\hline Skin (melanoma) & $\begin{array}{l}\text { C57BL/6 female } \\
\text { mice bearing } \\
\text { B16FIO tumors }\end{array}$ & $200 \mathrm{nmol} / \mathrm{kg}$ & $\begin{array}{l}\text { Sigma-Aldrich } \\
\text { (St. Louis, MO, USA) }\end{array}$ & ND & Y & 10 days & $\begin{array}{l}\downarrow \text { Metastatic foci } \\
\text { formation, } \uparrow \text { survival, } \\
\text { \lung tumor } \\
\text { nodules }\end{array}$ & $\begin{array}{l}\text { Menon et al. } \\
\text { (1995) }\end{array}$ \\
\hline
\end{tabular}

Note: A down arrow indicates a reduction or decrease and an up arrow indicates an increase. AgNOR, argyrophilic nucleolar organizer region; Bcl-2, B-cell lymphoma 2; Bcl-xL, B-cell lymphoma-extra-large; DEN, diethylnitrosamine, DMBA, 7,12-dimethylbenz[a]anthracene; MMP-2, matrix metallopeptidase-2; mTOR, mammalian target of rapamycin; ND, not determined; NF- $k B$, nuclear factor- $\kappa B$; STAT3, signal transducer and activator of transcription three; Zeb1, zinc finger E-box binding homeobox 1.

cell viability (Pereira et al., 2007). One study demonstrated that in vitro naringin treatment reduced the VEGF production in K562 human leukemia cells (Mellou et al., 2006). Naringin also increased the inhibitory activity of trypsin and enhanced the antiplatelet aggregation activity and cytotoxic activity against P388D1 (mouse lymphoid neoplasma) and L-1210 (mouse lymphocytic leukemia) cell lines (Kim et al., 1998). Another study also showed that in vitro naringin treatment suppressed cell proliferation and growth in Raji lymphoma cells (Ramanathan et al., 1992).

\section{Brain Cancer}

Gliomas are the most aggressive and frequent brain tumors, and regardless of progress in therapeutic management, they are still lethal. Accordingly, various therapeutic approaches are required to treat this aggressive disease (Martínez-Vélez et al., 2018). One study examined the antitumor effects of naringin treatment in vitro and in vivo. Results indicated that naringin had a toxic impact on the $\mathrm{U}-87$ cell line and reduced cancer cell proliferation and viability in a concentration-dependent way. Moreover, naringin administration also suppressed tubulogenesis and angiogenesis and reduced tumor size and cell invasion U-87 mouse xenograft tumor model (Table 4) (Aroui et al., 2020). Another study demonstrated that naringin could specifically suppress the focal adhesion kinase (FAK) activity and inhibit the FAKp-Try397 and its downstream pathway in glioblastoma cells. Treatment of U87 and U251 glioblastoma cells with naringin blocked cell proliferation through suppression of the FAK/cyclin D1 pathway and induction of cell apoptosis via the FAK/Bad pathway. It also inhibited cell metastasis and invasion by suppressing the FAK/MMPs pathway (Li et al., 2017). Another study demonstrated that naringin had inhibitory impacts on the migration, adhesion, and invasion of U87 and U373 human glioblastoma cells in a concentration-dependent way. Additionally, naringin inhibited several aspects of the MAPK signaling pathways, including p38, ERK, and JNK, and led to the downregulation of the MMP-9 and MMP-2 expression and enzymatic activities, contributing to the suppression of metastasis of glioblastoma cells (Aroui et al., 2016a). Treatment with naringin also reduced cell proliferation and viability in U251 glioma cells. Additionally, naringin suppressed cell invasion and migration via the modulation of matrix metallopeptidase-9 (MMP-9) and MMP2 expressions. Therefore, naringin might have therapeutic potential for the control of the invasiveness of malignant gliomas through suppressing the p38 signal transduction pathways (Aroui et al., 2016b). In an in vitro study, the treatment of U343 and U118 glioma cells with naringin showed a reduction in VEGF levels (Schindler and Mentlein, 2006). These findings have shown a new potential for exploring the capability of naringin as a promising therapeutic agent in gliomas.

\section{Breast Cancer}

Breast cancer is a heterogeneous group of tumors. Lately, a large number of personalized treatments for breast cancer have been introduced, with proven effectiveness (Cadoo et al., 2013). Natural products containing bioactive compounds are being used for both chemotherapy and cancer chemoprevention. Treatment with naringin suppressed proliferation and growth, and also increased apoptosis in MCF-7 cell lines (Puranik et al., 2019; Elansary et al., 2020). One study indicated that treatment with naringin alone or in combination with the sodium salt of carboxymethyl cellulose-phenyl alanine and sodium caseinate-phenyl alanine reduced viability and proliferation of MCF-7 cell line. Besides, naringin in hybrids had a greater cytotoxic effect in comparison to naringin alone (Basta et al., 2020). Moreover, treatment with naringin and its metal complexes decreased cell viability and proliferation and increased apoptosis in MCF-7 cell line (Atta et al., 2019). Based on the results, metal complexes of naringin demonstrated the highest cytotoxicity against cancer cells in comparison with naringin alone (Fazary et al., 2017). In another study, mononuclear palladium (II) complexes of naringin were synthesized, and the cytotoxic effect against MCF-7 cells was investigated. Results showed that naringin complexes reduced the viability and proliferation of breast cancer cells (Karami et al., 2018). Another study showed that treatment with naringin and its iron and copper complexes resulted in a reduction in the proliferation and viability of MCF-7 breast adenocarcinoma cell line (Selvaraj et al., 2014). One study, using different breast cancer cells (MCF-7 and MDA-MB-231), indicated that naringin reduced cell viability and promoted apoptosis and cycle arrest in breast cancer cells (Kabała-Dzik et al., 2018). 
TABLE 5 | Anticancer effects of naringin-based nano-drug delivery systems.

\begin{tabular}{|c|c|c|c|c|c|c|c|c|c|c|}
\hline $\begin{array}{l}\text { Nano- } \\
\text { formulation }\end{array}$ & $\begin{array}{c}\text { Cancer } \\
\text { type }\end{array}$ & $\begin{array}{l}\text { Study } \\
\text { type }\end{array}$ & $\begin{array}{c}\text { Cell } \\
\text { line/animal } \\
\text { model }\end{array}$ & Dose/Conc & Source & $\begin{array}{c}\text { Purity } \\
\text { (\%) }\end{array}$ & $\begin{array}{l}\text { Quality } \\
\text { control } \\
\text { reported? } \\
\text { (Y/N) }\end{array}$ & Duration & Outcomes & References \\
\hline $\begin{array}{l}\text { Gold-naringin } \\
\text { nanoclusters }\end{array}$ & Lung & In vitro & $\begin{array}{l}\text { A549 cell } \\
\text { line }\end{array}$ & $15-90 \mu \mathrm{g} / \mathrm{ml}$ & $\begin{array}{l}\text { Sigma-Aldrich } \\
\text { (St. Louis, MO, } \\
\text { United States) }\end{array}$ & ND & Y & $1-5$ days & $\downarrow$ Cell viability & $\begin{array}{l}\text { Sangubotla } \\
\text { et al. (2020) }\end{array}$ \\
\hline $\begin{array}{l}\text { Naringin-reduced } \\
\text { graphene oxide } \\
\text { nanosheets }\end{array}$ & Colon & In vitro & $\begin{array}{l}\text { HT-29 cell } \\
\text { line }\end{array}$ & $0.39-12.5 \mu \mathrm{M}$ & $\begin{array}{l}\text { KPI. (Shanghai, } \\
\text { China) }\end{array}$ & ND & Y & $24 \mathrm{~h}$ & $\begin{array}{l}\downarrow \text { Cell growth, } \\
\downarrow \text { cell } \\
\text { proliferation, } \\
\uparrow a p o p t o s i s\end{array}$ & $\begin{array}{l}\text { Han et al. } \\
(2020)\end{array}$ \\
\hline $\begin{array}{l}\text { Ti-Naringin-PBA- } \\
\text { ZnO } \\
\text { nanoparticles }\end{array}$ & Osteosarcoma & In vitro & $\begin{array}{l}\text { Saos- } 2 \text { cell } \\
\text { line }\end{array}$ & $98.6 \mu \mathrm{g} / \mathrm{ml}$ & $\begin{array}{l}\text { Aladdin } \\
\text { industrial co. } \\
\text { Ltd. (Shanghai, } \\
\text { China) }\end{array}$ & ND & Y & $1-7$ days & $\begin{array}{l}\uparrow A p o p t o s i s, \\
\uparrow R O S, \\
\uparrow M A P K / E R K \\
\text { pathway }\end{array}$ & $\begin{array}{l}\text { Yang et al. } \\
(2020)\end{array}$ \\
\hline $\begin{array}{l}\text { Nanostructured } \\
\text { lipid carrier- } \\
\text { containing } \\
\text { naringin and coix } \\
\text { seed oil }\end{array}$ & Liver & $\begin{array}{l}\text { In vitro; } \\
\text { In vivo }\end{array}$ & $\begin{array}{l}\text { HepG2 cell } \\
\text { line; BALB- } \\
\text { nu nude } \\
\text { mice with } \\
\text { HepG2 } \\
\text { xenografts }\end{array}$ & $\begin{array}{c}0.39-25 \mu \mathrm{M} ; \\
20 \mathrm{mg} / \mathrm{kg}\end{array}$ & $\begin{array}{l}\text { Shanghai } \\
\text { Standard } \\
\text { Technology } \\
\text { Co. Ltd. } \\
\text { (Shanghai, } \\
\text { China) }\end{array}$ & (>98\%) & Y & $1-10$ days & $\begin{array}{l}\downarrow \text { Cell } \\
\text { proliferation, } \\
\uparrow \text { apoptosis, } \\
\text { \cell viability, } \\
\downarrow \text { tumor } \\
\text { growth }\end{array}$ & $\begin{array}{l}\text { Zhu et al. } \\
\text { (2020) }\end{array}$ \\
\hline $\begin{array}{l}\text { PTX-NRG-MIC } \\
\text { micelles }\end{array}$ & Breast & In vitro & $\begin{array}{l}\text { MCF-7 cell } \\
\text { line }\end{array}$ & $\begin{array}{c}15-100 \mathrm{mg} / \\
\mathrm{ml}\end{array}$ & $\begin{array}{l}\text { Sigma-Aldrich } \\
\text { (Taufkirchen, } \\
\text { Germany) }\end{array}$ & ND & Y & $4-24 \mathrm{~h}$ & $\begin{array}{l}\downarrow \text { Cell growth, } \\
\downarrow \text { cell viability, } \\
\text { †intracellular } \\
\text { uptake }\end{array}$ & $\begin{array}{l}\text { Jabri et al. } \\
\text { (2019) }\end{array}$ \\
\hline $\begin{array}{l}\text { Naringin-PF68 } \\
\text { micelles }\end{array}$ & $\begin{array}{l}\text { Liver, breast } \\
\text { and colorectal }\end{array}$ & $\begin{array}{l}\text { In vitro; } \\
\text { In vivo }\end{array}$ & $\begin{array}{l}\text { Caco-2, } \\
\text { HepG2, and } \\
\text { MCF-7 cell } \\
\text { lines; female } \\
\text { Swiss albino } \\
\text { mice with } \\
\text { EAC cells }\end{array}$ & $\begin{array}{l}0.1-40 \mu \mathrm{M} ; \\
100 \mathrm{mg} / \mathrm{kg}\end{array}$ & $\begin{array}{l}\text { Sigma-Aldrich } \\
\text { co. (St louis, } \\
\text { MO, } \\
\text { United States) }\end{array}$ & ND & Y-HPLC & $1-7$ days & $\begin{array}{l}\downarrow \text { Tumor } \\
\text { growth, } \downarrow \text { cell } \\
\text { viability, } \downarrow \text { cell } \\
\text { proliferation, } \\
\downarrow \text { Tumor size }\end{array}$ & $\begin{array}{l}\text { Mohamed } \\
\text { et al. (2018) }\end{array}$ \\
\hline $\begin{array}{l}\text { PLGA } \\
\text { nanoparticles co- } \\
\text { encapsulating } \\
\text { naringin and } \\
\text { celecoxib }\end{array}$ & Lung & In vitro & $\begin{array}{l}\text { A549 cell } \\
\text { line }\end{array}$ & $0.78-100 \mu \mathrm{M}$ & $\begin{array}{l}\text { Sigma-Aldrich } \\
\text { (St. Louis, } \\
\text { MO, USA) }\end{array}$ & ND & Y & $10-70 \mathrm{~h}$ & $\begin{array}{l}\downarrow \text { Cell viability, } \\
\downarrow \text { cell } \\
\text { proliferation, } \\
\uparrow a p o p t o s i s\end{array}$ & $\begin{array}{l}\text { Said-Elbahr } \\
\text { et al. (2016) }\end{array}$ \\
\hline $\begin{array}{l}\text { Naringin- } \\
\text { conjugated gold } \\
\text { nanoparticles }\end{array}$ & $\begin{array}{l}\text { Breast and } \\
\text { prostate }\end{array}$ & In vitro & $\begin{array}{l}\text { MCF-7, } \\
\text { MDA-MB- } \\
\text { 231, T47D, } \\
\text { and PC-3 } \\
\text { cell lines }\end{array}$ & $30-100 \mu \mathrm{g} / \mathrm{ml}$ & $\begin{array}{l}\text { Sigma-Aldrich } \\
\text { (Chandigarh, } \\
\text { India) }\end{array}$ & ND & Y & $24 \mathrm{~h}$ & $\begin{array}{l}\downarrow \text { Cell viability, } \\
\downarrow \text { cell } \\
\text { proliferation }\end{array}$ & $\begin{array}{l}\text { Singh et al. } \\
(2016)\end{array}$ \\
\hline
\end{tabular}

Note: A down arrow indicates a reduction or decrease and an up arrow indicates an increase. EAC, Ehrlich ascites carcinoma; ERK, extracellular signal-regulated kinase pathway; MAPK, mitogen-activated protein kinase; ND, not determined; PLGA, poly D,L-lactide-co-glycolic acid copolymer; PTX-NRG-MIC, paclitaxel-and naringin-loaded mixed micelles; ROS, reactive oxygen species; Ti-naringin-PBA-ZnO, titanium-naringin-3-carboxyphenylboronic acid-zinc oxide.

Recently, there has been an increased interest in polyphenolic antioxidants because of their health advantages, which has resulted in the evaluation of novel polyphenolic compounds with increased antioxidant activity, such as naringin oxime. Treatment with naringin oxime reduced cell viability and proliferation in CMT-U27 canine mammary carcinoma cells. New oxime-type antioxidants, such as naringin oxime, can be synthesized from various flavanones, and these derivatives may be used as anticancer and radioprotective agents (Özyürek et al., 2014). In another study, triple-negative breast cancer cell lines (MDA-MB-231, MDA-MB-468, and BT-549) were used to investigate the antitumor effect and related mechanisms of naringin. Results showed that naringin suppressed cell proliferation and increased G1 cycle arrest and apoptosis, accompanied by enhanced p 21 and reduced survivin. Besides, the $\beta$-catenin signaling pathway was blocked by naringin treatment. Correspondingly, the anticancer potential of naringin was investigated in an in vivo condition, and naringin decreased tumor volume and weight in naringintreated MDA-MB-231 xenograft mice (Li et al., 2013a).

Irinotecan is a semi-synthetic derivate of camptothecin that belongs to the class of topoisomerase I inhibitors and has significant activity against various cancers. In vivo studies showed that treatment with naringin alone or combined with irinotecan suppressed tumor growth and tumor cell proliferation and promoted survival in Ehrlich ascites tumor cell bearing-mice. Besides, naringin enhanced irinotecan-induced cytotoxicity to cancer cells in mice bearing Ehrlich ascites tumors, while protecting normal cells (Benkovic et al., 2007; Oršolić et al., 2010; Knežević et al., 2011). Another study also showed that 


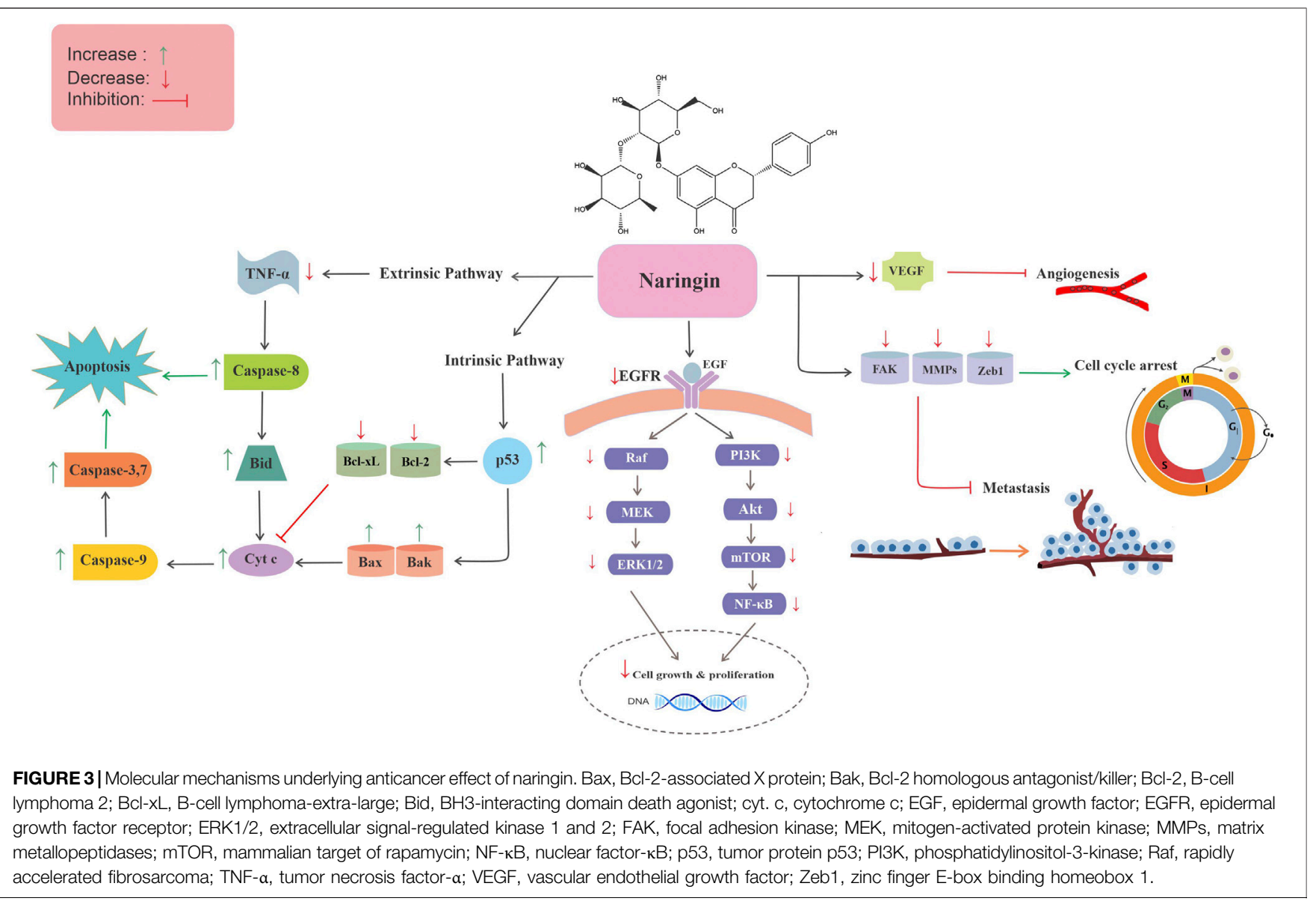

naringin increased cell death in Ehrlich ascites tumor cells (Menon et al., 1995). Naringin treatment also inhibited the development of mammary tumors and decreased the tumor weight in Sprague-Dawley rats induced by 7,12-dimethylbenz [a] anthracene (DMBA) (So et al., 1996). Numerous solid tumors induce vascular proliferation through the production of angiogenic factors, especially vascular endothelial growth factor (VEGF). One study demonstrated that naringin treatment decreased the level of secreted VEGF from MDAMB-231 cells (Schindler and Mentlein, 2006).

\section{Cervical Cancer}

Cervical cancer is the second-highest cause of death among women between the ages of 20 and 39 years (Fidler et al., 2017). Although chemotherapy is the standard therapeutic option, the survival rates of patients with cervical cancer are poor and need improvement via investigation of specific antitumor agents with less adverse effects on healthy cells (Pfaendler and Tewari, 2016). Hence, novel therapeutic targets are urgently required for the improvement of cervical cancer therapeutics. One study evaluated the antiproliferative effect and the associated mechanism of naringin-induced cell death in C33A, SiHa, and HeLa human cervical cancer cell lines. Results demonstrated that naringin treatment reduced cell viability and induced endoplasmic reticulum stress-mediated apoptosis. It also inhibited the $\mathrm{Wnt} / \beta$-catenin pathway by reducing the protein expression and phosphorylation of glycogen synthase kinase-3 $\beta$ (Ser9) and $\beta$-catenin (Ser576), while simultaneously induced cell cycle arrest (Chen et al., 2020). In vitro treatment of SiHa cells with naringin decreased cell proliferation and viability by $\mathrm{G} 2 / \mathrm{M}$ cell cycle arrest and induced apoptosis via DwM disruption, and intrinsic and extrinsic pathway activation (Ramesh and Alshatwi, 2013).

The doxorubicin (DOX) application in cervical cancer chemotherapy is severely hampered by the DOX side effects. The formation of DOX-iron complexes by oxygen free radicals plays an important role in DOX-induced toxicity (Myers, 1998). Fortunately, flavonoids have excellent radical scavenging and iron-chelating properties (Kaiserová et al., 2007), and they can act as an effective modulator for DOX-induced toxicity. Treatment with naringin, DOX, and their combination reduced cell proliferation in HeLa human cervical cancer cells and suppressed HeLa cervical tumor and induced cell apoptosis in tumor-bearing mice. More importantly, the combined treatment had a greater antitumor effect in comparison to either agent alone (Liu et al., 2017). Another study showed that naringin treatment suppressed plasma membraneassociated sialidase (NEU3), and the NEU3-inhibitory effect of naringin promoted GM3 accumulation in HeLa cells, resulting in epidermal growth factor receptor (EGFR)/ERK signaling 
TABLE 6 | Anticancer effects of naringin based on google patents and US patents registry.

\begin{tabular}{|c|c|c|c|c|c|}
\hline Patent NO & Cancer types & Subjects & Results & Major outcomes & References \\
\hline ES2519040T3 & Liver and lung cancers & $\begin{array}{l}\text { Cell lines, } \\
\text { animals, and } \\
\text { humans }\end{array}$ & $\begin{array}{l}\text { Inhibiting TGF- } \beta 1 \text { signaling pathway; } \\
\text { improving serum IFN- } \gamma\end{array}$ & $\begin{array}{l}\text { Treating or preventing } \\
\text { fibrosis and tumors }\end{array}$ & Liang et al. (2008) \\
\hline US7326734B2 & Bladder cancer & Cell lines & Inhibiting cell proliferation & $\begin{array}{l}\text { Treating or preventing } \\
\text { tumors }\end{array}$ & Zi et al. (2004) \\
\hline US10307393B2 & $\begin{array}{l}\text { Pulmonary carcinoma, esophageal } \\
\text { carcinoma, breast carcinoma, and } \\
\text { mediastinum tumors }\end{array}$ & $\begin{array}{l}\text { Cell lines and } \\
\text { animals }\end{array}$ & $\begin{array}{l}\text { Reducing the release of the inflammatory } \\
\text { factors (IL-1 } \beta, \text { IL- } 6 \text {, TNF- } \alpha \text {, TGF- } \beta \text {, and } \\
\text { IFN- } \gamma \text { ) }\end{array}$ & $\begin{array}{l}\text { Radiotherapy } \\
\text { protection and treating } \\
\text { tumors }\end{array}$ & Liang et al. (2016) \\
\hline JP2005508312A & $\begin{array}{l}\text { Colorectal, cervical, gastric, lung } \\
\text { cancer, malignant glioma, ovarian, } \\
\text { and pancreatic cancers }\end{array}$ & $\begin{array}{l}\text { Cell lines, } \\
\text { animals, and } \\
\text { humans }\end{array}$ & Inhibiting MDR1 gene expression & $\begin{array}{l}\text { Treating or preventing } \\
\text { tumors }\end{array}$ & $\begin{array}{l}\text { Gunther and } \\
\text { Reinhold, (2005) }\end{array}$ \\
\hline KR20060120101A & $\begin{array}{l}\text { Prostate, colorectal, and liver } \\
\text { cancers }\end{array}$ & Cell lines & $\begin{array}{l}\text { Binding to EGR-1-like promoter sequences } \\
\text { to modulate the expression of cancer } \\
\text { related genes ( } 21 \text { and p53) }\end{array}$ & $\begin{array}{l}\text { Treating or preventing } \\
\text { tumors }\end{array}$ & Wong et al. (2004) \\
\hline
\end{tabular}

EGR1, early growth response 1; IFN- $\gamma$, interferon- $\gamma$; IL-1 $\beta$, interleukin-1 $\beta$; IL-6; interleukin-6; MDR1, multi-drug resistance-1; TGF- $\beta 1$, transforming growth factor- $\beta 1$; TNF- $\alpha$, tumor necrosis factor- $\alpha$.

attenuation accompanied by a reduction in cell growth and enhancement of apoptotic cells (Yoshinaga et al., 2016). Additional studies demonstrated that naringin decreased proliferation and viability and also induced apoptosis of $\mathrm{HeLa}$ cervical adenocarcinoma cells (Ramanathan et al., 1992; Elansary et al., 2020) by blocking the NF- $\mathrm{B} /$ cyclooxygenase-2 (COX-2)caspase-1 pathway (Zeng et al., 2014).

\section{Colon Cancer}

Colorectal cancer (CRC) is one of the most frequent malignant tumors. The primary methods for CRC treatment are radiotherapy, chemotherapy, and surgery. However, because of the challenges rising from drug resistance, it is vital to explore additional effectual compounds targeting alternative signaling pathways (Van der Jeught et al., 2018). Studies show that naringin has antineoplastic activities and treatment with naringin can reduce proliferation, and viability, while also enhancing apoptosis in HT-29 colon adenocarcinoma (Elansary et al., 2020) and CT26 colorectal cancer cell lines (Zhou et al., 2018). Another study indicated that treatment of human colon tumor cell lines (HCT116 and SW620) with naringin suppressed the CRC cell viability and proliferation, and promoted apoptosis by suppressing the phosphoinositide-3 kinase (PI3K)/protein kinase-B (also known as Akt)/mammalian target of rapamycin (mTOR) signaling pathway (Chidambara Murthy et al., 2012; Cheng et al., 2020). Naringin treatment also induced apoptosis in Colo 205 and Colo 320 human colon cancer cells (Ugocsai et al., 2005). However, one study indicated that naringin had no inhibitory effect on cell growth of COLO 320HSR, COLO 205, and HT 29 colon cancer cells (Shen et al., 2004). In another study, naringin treatment interestingly abrogated cell growth and proliferation in human colon adenocarcinoma cells (HT29) in a concentration-dependent manner, and bio-transformed naringin showed significant antiproliferative activity (Ferreira et al., 2013). Also, treating HCT116 human colorectal carcinoma cells with naringin and synthesized binary and ternary platinum and vanadium metal complexes has shown moderate cytotoxic activities, with enhanced apoptosis and reduced cell viability and proliferation (Fazary et al., 2017). In another study, the antitumor effect of naringin was examined alone and in hybrids with SCMC-PA and SC-PA conjugates against the HCT116 colon cancer cells. Results showed that naringin, individually or in hybrids, reduced the proliferation and viability of colon cancer cell lines (Basta et al., 2020). Naringin also increased the inhibitory activity of trypsin and enhanced the antiplatelet aggregation activity and cytotoxic activity toward SNU-C4 human colon cancer cells (Kim et al., 1998).

In an in vivo study, the cytotoxic impacts of naringin on azoxymethane (AOM)/dextran sulfate sodium (DSS)-induced colorectal carcinogenesis and inflammation in C57BL/6 mice were investigated. Results indicated that naringin-treatment reduced tumor size and growth in C57BL/6 mice through inhibiting robust endoplasmic reticulum stress-induced autophagy in colorectal mucosal cells (Zhang et al., 2018b). Another study showed that naringin reduced tumor cell proliferation and promoted apoptosis in AOM-injected Sprague-Dawley rats (Vanamala et al., 2006). Glyoxalase-I (GLO-I), the ubiquitous detoxification system component, is involved in methylglyoxal (MG) conversion to D-lactate in the glycolytic pathway and has been shown to be regularly overexpressed in several cancer cells (Thornalley, 2008). One study showed that naringin reduced GLO-I activity and suppressed cell proliferation and viability in Caco-2 human epithelial colorectal adenocarcinoma cells (Yadav et al., 2016). However, naringin had no cytotoxic impact on Caco-2 and HT29 human colon adenocarcinoma cells (Kuo, 1996).

\section{Esophageal/Head and Neck Cancer}

Esophageal carcinoma is a relatively rare cancer with a high death rate worldwide (Pennathur et al., 2013). DOX is an important chemotherapy agent that has been widely used as an antitumor agent (Hajjaji et al., 2012). Recent works demonstrated that the combination of herbal medicines and chemotherapy drugs have several advantages. One study showed that treatment with naringin alone or combined with DOX reduced cell viability 
and proliferation in YM1 esophageal cancer cell line, and reduced tumor size in xenograft mice tumor model (Tajaldini et al., 2020). An in vivo study indicated that naringin treatment markedly reduced tumor size and growth, and also significantly decreased tumor burden in the hamster cheek pouch oral cancer model (Miller et al., 2008). A separate study demonstrated that in vitro treatment with naringin reduced cell viability in HEp2 human laryngeal carcinoma cells. Naringin also reduced lipid peroxidation and enhanced cytochrome P-450 (CYP) 1A1 expression in laryngeal cancer cell lines (Durgo et al., 2007).

\section{Liver Cancer}

Irrespective of the combined efforts of researchers and clinicians around the world, there has been a continuous increase in the incidence rate of hepatocellular carcinoma (HCC) over the last two decades (Alwhibi et al., 2017). In one study, HepG2 cell lines were used to examine the possible antiproliferative and cytotoxic effects of naringin and/or methotrexate (MTX). Naringin and/or MTX treatment exhibited cytotoxic and antiproliferative effects and induced apoptosis in HepG2 hepatocellular cancer cells via Bax activation and downregulation of Bcl-2 protein expression in a concentration-dependent way. Additionally, naringin potentiated the viability and cytotoxic effect of MTX in HepG2 cells (Elsawy et al., 2020). In another study, naringin substantially reduced the viability and proliferation of HepG2 cells (Syed et al., 2020). Naringin treatment also significantly suppressed proliferation, upregulated the expression of microRNA (miR)-19b, and promoted apoptosis in HepG2 cells. Additionally, it downregulated the Bcl-2 protein expression and upregulated the Bax protein expression to trigger apoptosis (Xie et al., 2017). Naringin blocked proliferation and enhanced early apoptosis of HepG2 cells via activation of Bid proteolysis mediated by caspase- 8 and caspase9. Therefore, the intrinsic and extrinsic pathways were linked in naringin-mediated apoptosis in HepG2 cells. Additionally, increased expression levels of pro-apoptotic Bak and Bax proteins and reduced levels of anti-apoptotic Bcl-xL protein were demonstrated, verifying the participation of the mitochondrial pathway (Banjerdpongchai et al., 2016b). Treatment with naringin reduced proliferation, viability, and growth and promoted apoptosis in HepG2 cells through extrinsic and intrinsic pathways (Banjerdpongchai et al., 2016a; Zhou et al., 2018). In another in vitro study, the cytotoxic effect of naringin in different hepatocellular carcinoma cells (Huh-7, HepG2, and HA22T) was investigated. Treatment with naringin inhibited MMP-9 transcription by suppressing NF- $\mathrm{KB}$ and activator protein-1 (AP-1) activity. It inhibited 12-O-tetradecanoylphorbol 13acetate (TPA)-induced AP-1 activity by suppressing the phosphorylation of the c-Jun $\mathrm{N}$-terminal kinase (JNK) and ERK signaling cascades, and it inhibited TPA-induced

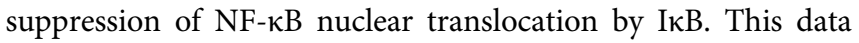
demonstrates that naringin inhibits the metastasis and invasion of HCC cells by suppressing multiple signal transduction pathways (Yen et al., 2015). In another study, treatment with various concentrations of naringin hampered cell growth and cell proliferation of HepG2 cells and biotransformation with tannase significantly increased its antiproliferative activity (Ferreira et al., 2013).

Diethylnitrosamine (DEN) is one of the major environmental carcinogens and hepatotoxins (Sreepriya and Bali, 2005). In an in vivo experiment, the apoptotic and antiproliferative effect of naringin on DEN-induced liver carcinogenesis in male Wistar rat models was evaluated. Results showed that treatment with naringin significantly reduced the levels of proliferating cell nuclear antigen (PCNA) and the argyrophilic nucleolar organizer region (AgNOR)/nuclei. Naringin also suppressed proliferation and enhanced apoptosis in the liver cancer cells of rats (Thangavel and Vaiyapuri, 2013). In one study, cytotoxic actions of the synthesized binary and ternary platinum and vanadium metal complexes of naringin were evaluated using HepG2 cells. Results demonstrated that treatment with naringin and its metal complexes reduced cell viability and proliferation, and enhanced apoptosis in liver cancer cells. Additionally, metal complexes of naringin had a greater cytotoxic effect compared with naringin alone (Fazary et al., 2017). Moreover, naringin treatment of Hep1 and HA22T human liver cancer cells resulted in the suppression of cell viability and growth (Hsiao et al., 2007a). In another study, naringin treatment increased cytotoxic and antiplatelet aggregation activities and enhanced trypsin inhibition in HepG2 cells (Kim et al., 1998). However, at least one study demonstrated that naringin did not suppress cell growth in Hepa1c1c7 mouse liver cancer cell line (Campbell et al., 2006).

\section{Lung Cancer}

Lung carcinoma is one of the main causes of cancer-related death worldwide (Jemal et al., 2002). The high death rate of lung cancer is possibly due to challenges associated with diagnosis and a high metastatic potential (Sangodkar et al., 2010). Consequently, it is essential to determine non-toxic alternative therapies to improve the responsiveness of lung cancers to chemotherapy. Treatment with naringin reduced viability and growth in the A549 human lung adenocarcinoma (Nie et al., 2012), and Lewis lung carcinoma (LLC) cell lines (Hsiao et al., 2007a). Naringin treatment also suppressed cell viability and proliferation, and promoted apoptosis in human small cell lung cancer cells (H69AR) by regulation of miR-126/Akt/mTOR/PI3K pathway via miR-126 overexpression and suppression of VCAM-1, p-Akt, PI3K, NF- $\kappa B$, and p-mTOR pathways (Chen et al., 2018). In one study, the antimetastatic properties of naringin were evaluated, and results showed that treating A549 lung cancer cells with naringin resulted in a reduction of cell invasion, cellular motility, cell viability, and cell-matrix adhesion (Hsiao et al., 2007b). In a separate study, treatment with naringin increased the inhibitory activity of trypsin and enhanced its cytotoxic and anti-platelet aggregation activity against A549 cells (Kim et al., 1998).

Ruthenium is a great alternative to platinum due to its extensive variety of oxidation states and its capability to form complexes with bioactive ligands (Jayakumar et al., 2018). Naringin was used to fabricate a ruthenium complex with anticancer activity. Results showed that a naringin-ruthenium (II) complex reduced cell viability and proliferation, and promoted apoptosis in A549 human lung adenocarcinoma 
(Garcia et al., 2019). Also, treatment with naringin alone and in combination with transition metal ions [Ag (I), Y (III), and Ru (III)] reduced cell growth and viability, and enhanced apoptosis in A549 human lung adenocarcinoma. Additionally, results showed that transition metal ions enhance the naringin activity when they are coordinated with each other (Atta et al., 2019). Another study showed that treatment of A549 cells with naringin promoted accumulation of GM3 through inhibition of NEU3 and resulted in the attenuation of ERK/EGFR signaling accompanied by a reduction in cell growth (Yoshinaga et al., 2016).

\section{Neuroblastoma}

Neuroblastoma is the most frequent extracranial solid tumor in children. There is an increasing interest in using plant-derived dietary compounds for the treatment of several solid tumors, including malignant neuroblastoma (Yamane and Kato, 2012). Naringin treatment reduced cell viability and promoted apoptosis in rotenone-treated SH-SY5Y human neuroblastoma cell line through suppression of P38 and JNK phosphorylation, as well as activation of caspase- 3 and caspase-9 (Kim et al., 2009).

\section{Ovarian Cancer}

Ovarian cancer is a heterogeneous group of neoplasms, which is classified based upon type and degree of differentiation. It is one of the most deadly female reproductive system malignant tumors (Cho and Shih, 2009). The most efficient treatment for ovarian cancer is platinum-based chemotherapy and surgical cytoreduction (Jessmon et al., 2017). Resistance to platinumbased agents is one of the difficulties of ovarian cancer treatment using pharmacological agents (Choi et al., 2008). Therefore, investigating novel agents with low toxicity and high efficacy that can also reduce resistance to platinum-based agents, is very important. NF- $\kappa \mathrm{B}$ is highly expressed in cisplatin-resistant ovarian cancer cell lines and has a crucial role in the drug resistance of ovarian cancer cells (Choi et al., 2008). One study demonstrated that the inhibitory effect of naringin was associated with inhibition of the NF- $\mathrm{kB}$ signaling pathway, and treatment with naringin significantly reduced $\mathrm{P}$-glycoprotein (P-gp) and NF- $\kappa B$ expression in a concentration-dependent way in SKOV3/CDDP cisplatin-resistant human epithelial ovarian cancer cell line (Zhu et al., 2018). Another study also indicated that naringin downregulated COX-2 and NF- $\mathrm{BB}$ expression in a concentration-dependent way in SKOV3/ CDDP cells (Zhu et al., 2017). In an in vivo study, treatment with naringin reduced ovarian tumor size and weight in tumorbearing mice. Naringin also induced apoptosis by decreasing c-Myc, Bcl-2, surviving, cyclin D1, and Bcl-xL and increasing caspase-3 and caspase-7 levels in ovarian tumor cells. Such suppression may be related to the $\mathrm{NF}-\kappa \mathrm{B}$ signaling pathway regulation (Cai et al., 2018). Interestingly, at least one study indicated that naringin had no obvious inhibitory impact on cell growth and proliferation of OVCAR-3 human ovarian cancer cell line (Luo et al., 2008).

\section{Prostate Cancer}

Prostate cancer is the second most common cancer in men and the fourth most common cancer overall (Ferlay et al., 2015). The combined consumption of nutraceutical agents and chemotherapeutic drugs is a great approach for increasing the therapeutic anticancer impacts, as well as easing adverse effects of chemotherapy and drug resistance (de Oliveira Júnior et al., 2018). Atorvastatin, a 3-hydroxyl-3-methylglutaryl coenzyme A reductase inhibitor, has demonstrated antitumor activity in prostate cancer (Allott et al., 2017). One study examined the anticancer effect of naringin in combination with atorvastatin on PC-3 and LNCaP prostate cancer cell lines. Results demonstrated that combined treatment of atorvastatin and naringin synergistically induced apoptosis, reduced cell growth, suppressed invasion and migration, and potently inhibited AR, p-STAT3, survivin, p-Akt, and Bcl-2 expression levels. Additionally, treatment with naringin alone or combined with atorvastatin suppressed the tumor growth in tumor-bearing SCID mice, and the combined treatment demonstrated a greater inhibitory effect compared to either compound alone (Wu et al., 2019). In another study, PC3, DU145, and LNCaP cell lines were treated with different concentrations of naringin, paclitaxel, and their combinations. Treatment with naringin individually or combined with paclitaxel suppressed cell proliferation and cell survival in a concentration- and timedependent way through induction of apoptosis and cycle arrest as well as decreased cell migration via inhibition of NF$\kappa \mathrm{B}, \mathrm{ERK}$, and Akt signaling and upregulation of phosphatase and tensin homologue (PTEN) expression. Taken together, naringin synergistically promoted the paclitaxel cytotoxic impact in $\mathrm{PCa}$ cell lines (Erdogan et al., 2018). In an in vitro study, treatment with naringin decreased cell viability and proliferation as well as enhanced apoptosis in DU145 prostate cancer cell line. Naringin also enhanced oxidative stress and had a genotoxic effect on prostate cancer cells (Lewinska et al., 2015).

\section{Sarcoma}

Even though adjuvant chemotherapy has led to the improved survival rates in osteosarcoma patients, the development of multidrug resistance has seriously influenced prognosis and limited the success of therapeutic attempts (Davis et al., 2018). Hence, novel and effective drugs for osteosarcoma treatment are required. One study showed that naringin treatment suppressed cell migration, invasion, and proliferation, and promoted apoptosis and cell cycle arrest in MG63 and U2OS human osteosarcoma cells through blockage of zinc finger E-box binding homeobox 1 (Zeb1), which plays a role in tumor metastasis. Additionally, naringin decreased tumor nodule formation and expression of MMP-2, Bcl-2, and cyclin D1 in the livers of mice bearing MG63 osteosarcoma cell line (Ming et al., 2018). However, another study indicated that naringin did not affect the MG-63 osteosarcoma cells' growth rate (Zhang et al., 2018a). In vitro treatment of JJ012 human chondrosarcoma cells with naringin reduced cell invasion and migration through the suppression of VCAM-1 expression by enhancing miR-126 expression (Tan et al., 2014).

In an in vivo study, naringin treatment demonstrated significant inhibition of tumor growth in male ddY mice bearing S180 sarcoma cancer cells (Kanno et al., 2005). In vivo treatment of naringin decreased TNF- $\alpha$ and IL-6 levels, 
suppressed tumor growth, and increased the survival rate in Wistar rats bearing W256 carcinosarcoma cells (Camargo et al., 2012).

\section{Skin Cancer}

Melanoma is the leading cause of mortality from skin cancer (Siegel and Naishadham, 2013). Historically, melanoma has been refractive to chemotherapy which provides very low response rates and very few beneficial effects in overall survival. Therefore, multiple targeted therapeutic approaches have been examined (Ascierto et al., 2013). Treatment of A375 and A875 melanoma cell lines with naringin promoted cycle arrest and apoptosis, and also suppressed cell proliferation and growth in a concentration-dependent way. Naringin also suppressed c-Src and cancer cell metabolism through suppression of the c-Src/Akt signaling pathway, leading to a decrease in cell migration and invasion (Guo et al., 2016). Another study demonstrated that naringin treatment reduced the metastatic foci formation and increased the survival rate in mice bearing B16FlO melanoma cells (Menon et al., 1995). Another study also indicated that in vitro treatment of naringin reduced cell invasion in MO4 mouse melanoma cell line (Bracke et al., 1991). In an in vitro study, the anticancer effect of the naringin-derived copper (II) complex was investigated. The results showed that treatment of $\mathrm{B} 16 \mathrm{FlO}$ melanoma with naringin or naringin-Cu (II) complex reduced cell proliferation and growth, increased cell death, and decreased diphenylpicrylhydrazyl radical (DPPH). Additionally, it demonstrated that the naringin-Cu (II) complex had higher anti-inflammatory, antioxidant, and anticancer activities in comparison to free naringin without decreasing cell viability (Pereira et al., 2007).

\section{Stomach Cancer}

Gastric cancer is the fourth most detrimental cancer-related death in the world (Torre et al., 2015). A large number of cancer cases and mortality could be avoided with early detection, using the phytomedicine intervention as an alternative to radiotherapy and chemotherapy. One study investigated the mechanism behind naringin-mediated autophagic cell death in AGS gastric cancer cell line. Naringin treatment promoted lysosomal membrane permeabilization through suppression of Akt/mTOR/PI3K signaling cascade, resulting in lysosomal cell death protein cathepsin D-mediated ERK1/2-p38 MAPKs activation through $\mathrm{Bcl}-\mathrm{xL}$ decrease, and $\mathrm{Bad}, \mathrm{BH} 3$, and ROS increase in autophagymediated cell death in AGS cell line. Additionally, rapamycin pretreatment with naringin indicated a significant reduction in mTOR phosphorylation and enhancement in LC3B activation in AGS cells compared with naringin treatment alone (Raha et al., 2020). In another study, naringin treatment suppressed viability and growth in the AGS (human gastric epithelial 108 adenocarcinoma) cells (Hsiao et al., 2007a). Naringin treatment of AGS cells induced autophagy-mediated growth suppression through suppression of PI3K/Akt/mTOR cascade, and potentially via activation of MAPKs (Raha et al., 2015). Furthermore, treatment with naringin increased the inhibitory activity of trypsin and increased the cytotoxic activity and antiplatelet aggregation activity against SNU-1 human stomach cancer cells (Kim et al., 1998).

\section{Thyroid Cancer}

Thyroid cancer is the most frequent malignant tumor of the endocrine system (Kweon et al., 2014). The current approach for thyroid cancer treatment includes thyroid hormone inhibition therapy, surgical treatment, adjuvant radiotherapy, and isotope iodine-131 therapy. However, there are several disadvantages for these different types of treatment (Tang et al., 2017; ZivancevicSimonovic et al., 2017). Hence, the development of low-toxic, effective, and new inhibitors is important in improving the survival rates of thyroid cancer patients. One study showed that in vitro treatment of SW1736 and TPC-1 thyroid cancer cells with naringin reduced cell proliferation and promoted apoptosis via suppression of PI3K/Akt pathway (Zhou et al., 2019).

\section{NANOSTRUCTERED FORMULATIONS OF NARINGIN IN COMBATING MALIGNANCIES}

In the past two decades, nanotechnology-based delivery systems have gained interest as a method to overcome the challenges associated with solubility, bioavailability, distribution, low therapeutic index, toxicity and targeting of conventional chemotherapeutic drugs as well as anticancer natural compounds (Feng and Mumper, 2013; Davatgaran-Taghipour et al., 2017; Kashyap et al., 2021; Lagoa et al., 2020). Naringin is one of the most fascinating phytopharmaceuticals that has been broadly examined for different biological activities. Yet, its suboptimal bioavailability, limited permeability, and low water solubility have restricted its use. A useful approach to overcome these difficulties is encapsulation of the agent into different nanosized delivery vehicles (Mohamed et al., 2018).

Gold-naringin nanoclusters (GNNC) showed cytotoxic effects against A549 lung cancer cells and reduced the cell viability with increased concentrations of GNNC. At the same time, the WI-38 levels in lung normal cells remained elevated, even after treatment with high doses of GNNC (Sangubotla et al., 2020) (Table 5).

With advances in nanotechnology and the extensive use of graphene, it has become essential to evaluate the possible disadvantages of graphene. Thus, most of the current studies are focused on different modified graphene. Naringin-reduced graphene oxide nanosheets (rGO@Nar), promotes cytotoxicity in the colon cancer cells (HT-29) through increased apoptosis and reduced cell viability and proliferation. The rGO@Nar plus naringin is more efficient toward colon cancer in comparison to rGO@Nar or naringin alone. Additionally, it has been shown that rGO@Nar together with naringin and rGO@Nar can efficiently eliminate tumor cells without affecting normal cells (Han et al., 2020).rGO@Nar may be a promising agent for assessment in the in vivo models of colon cancers.

After bone tumor resection, the large deficits are normally reconstructed with titanium ( $\mathrm{Ti}$ )-based metallic endoprosthesis. When applied in osteosarcoma resection, Ti implant-related infection and tumor recurrence were determined as two crucial factors for failure of implantation. Ti-naringin-3carboxyphenylboronic acid (PBA)-zinc oxide ( $\mathrm{ZnO})$ 
nanoparticles reduce infection and tumor recurrence and induce Saos-2 osteosarcoma cells apoptosis through activation of ROS/ ERK signaling. In vitro cellular experiments showed that these nanoparticles could promote the proliferation and growth of osteoblasts (Yang et al., 2020). Nevertheless, in vivo experiments are required for understanding the anticancer properties of Ti-Naringin-PBA-ZnO nanoparticles in osteosarcoma.

Lipid-based nanoparticles are another delivery system that has particular benefits due to their unique properties, such as biodegradation, biological compatibility, multiple routes of administration, and convenient and easy industrial scale-up process (Rout et al., 2018). Nanostructured lipid carriers containing naringin and coix seed oil (NCNLCs) were successfully fabricated, and their cytotoxic activity was evaluated. NCNLCs reduced proliferation and viability and promoted apoptosis in HepG2 liver cancer cells and had a greater cytotoxic effect compared with free naringin, NONLCs, and NDNLCs. Moreover, the in vivo synergistic anticancer efficacy was evaluated in NCNLCs in xenograft tumor mice models and results showed that NCNLCs upregulated the IL10 and IL-6 expression in the serum of tumor-bearing mice and inhibited tumor growth (Zhu et al., 2020).

The development of multidrug resistance (MDR) has restricted the efficacy of chemotherapeutic agents. Co-delivery of natural flavonoids with anticancer drugs in polymeric micelles is a potentially significant approach for overwhelming MDR and enhancing their anticancer efficacy. Paclitaxel co-encapsulation with naringin in mixed polymeric micelles increased in vitro cytotoxicity toward MCF-7 breast cancer cell line. Paclitaxel- and naringin-loaded mixed (PTX-NRG-MIC) micelles synergistically reduced the growth and viability of MCF-7 cell line and increased their intracellular uptake. Additionally, PTX-NRG-MIC micelles are more effective toward breast cancer when compared to naringin or paclitaxel (Jabri et al., 2019). Yet, in vivo experiments are required to confirm the active targeted delivery of PTX-NRG-MIC micelles.

Naringin polymeric micelles based on pluronic F68 were fabricated and their in vitro cytotoxicity was assessed against different cancer cell lines. Naringin-PF68 micelles reduced the viability and proliferation of Caco-2, HepG2, and MCF-7 cells. Furthermore, Swiss albino mice were used to evaluate the anticancer activity of naringin-PF68 micelles compared to the free drug. Results showed that PF68 micelles of naringin reduced tumor size and inhibited tumor growth in tumor-bearing mice. Naringin-PF68 micelles had a greater cytotoxic effect when compared with free naringin (Mohamed et al., 2018).

In another study, poly D,L-lactide-co-glycolic acid copolymer (PLGA) nanoparticles co-encapsulating celecoxib and naringin were synthesized and induced apoptosis and inhibited proliferation in the A549 cells in a concentration-dependent manner. They also showed greater cytotoxic activity on A549 cells in comparison to the combination of free drugs, while exhibiting significant safety on healthy lung tissues (SaidElbahr et al., 2016).

In another study, gold nanoparticles (AuNPs) were synthesized using naringin as a reducing and stabilizing agent to create nano-theranostic agents. Naringin-conjugated gold nanoparticles (N-AuNPs) were evaluated with cytotoxicity and hemolysis assays, which showed their biocompatibility with MDA-MB-231 cell lines and normal red blood cells, while also demonstrating their potential to induce cell death in T47D, PC-3, and MCF-7 cell lines. In vivo studies must be conducted to confirm the active targeted delivery of N-AuNPs in cancer (Singh et al., 2016).

Taken together, results show that the nano-drug delivery systems have the capability to overwhelm the pharmacokinetic restrictions of naringin, highlighting its impacts on cancer therapy. Further research is required for designing surfacemodified nano-formulations of naringin to achieve adjusted drug delivery systems.

\section{PHARMACOKINETICS AND TOXICITY OF NARINGIN}

After a single oral administration $(42 \mathrm{mg} / \mathrm{kg}$ ) of naringin in aged rats, minor differences were shown in the area under the plasma concentration-time curve (AUC) of total naringenin and naringin gained in the gastrointestinal tract, stomach, liver, muscle, kidney, and brain between male and female aged rats. It must be mentioned that the AUC of naringin in the trachea $(3,140 \%)$ and lung $(1,250 \%)$ of female rats in comparison to male rats were considerably higher, indicating that naringin may exhibit gender differences in the treatment of respiratory diseases in elderly individuals (Zeng et al., 2019). In multiple-dose studies, no considerable accumulation of naringenin was detected in rats, dogs, and humans. In single-dose studies, various pharmacokinetic parameters in females, including the elimination half-life $\left(\mathrm{t}_{1 / 2}\right)$ (naringenin, rats, oral, $42 \mathrm{mg} / \mathrm{kg}$ ), AUC (naringin, humans, $160 \mathrm{mg}$ (high-fat diet); naringin, rats, oral, $21 \mathrm{mg} / \mathrm{kg}$; and naringenin, humans, $40 \mathrm{mg}$ ), peak plasma concentration $\left(\mathrm{C}_{\max }\right)$ (naringenin, humans, $40 \mathrm{mg}$ ), and time to reach $C_{\max }\left(\mathrm{T}_{\max }\right)$ (naringenin, rats, oral, $168 \mathrm{mg} / \mathrm{kg}$ ) were considerably higher than those of males, while a small number of pharmacokinetic parameters in females, including AUC (naringin, humans, $40 \mathrm{mg}$ ) and $\mathrm{C}_{\max }$ (naringenin, rats, i.v., $42 \mathrm{mg} / \mathrm{kg}$ ) were significantly lower than those of males. In multiple-dose studies, considerably greater female parameters were only detected in rats (naringenin, accumulation index, $1.79 \pm 0.457$ and naringin, $\mathrm{T}_{\max }, 2.70 \pm 1.48 \mathrm{~h}$ ) (Bai et al., 2020). The plasma drug concentration-time curves indicate that the oridonin AUC 0-24h value was nearly three times larger compared to naringin, while the naringin dose was approximately four times larger compared to oridonin, indicating that the oridonin absorption in rats is higher than naringin (Jin et al., 2015). Naringin administration $(15 \mathrm{mg} / \mathrm{kg}$ ) suppressed the P-gp function and considerably enhanced the candesartan intestinal absorption by 3.2 times (Surampalli et al., 2015). After administration of 600 and $1,000 \mathrm{mg} / \mathrm{kg}$ naringin through the duodenal cannula, the naringin average $\mathrm{C}_{\max }$ in portal plasma was measured at $18.8 \pm 3.8 \mathrm{~min}$, while the naringin absorption ratios in lymph fluid and portal plasma were nearly 4.1 and 95.9, respectively. This suggests that naringin may be 
absorbed through portal blood and concentrations may be reduced via bile excretion (Tsai and Tsai, 2012). In membrane toxicity studies, naringin administration $(15 \mathrm{mg} / \mathrm{kg}, \mathrm{w} / \mathrm{w})$ did not cause any toxicity; but, it insignificantly increased the protein release from the intestinal membrane (Surampalli et al., 2015). The sub-chronic and acute toxicology of naringin was indicated to be almost non-toxic for Sprague-Dawley rats, and the naringin no-observed-adverse-effect-level (NOAEL) in rats was larger than $1,250 \mathrm{mg}$ per $\mathrm{kg}$ per day after oral administration for 13 weeks (Li et al., 2013b). No intestinal membrane impairment was noted in the naringin presence through measurement of the alkaline phosphatase and protein release (Surampalli et al., 2015).

\section{CONCLUSIONS AND FUTURE DIRECTIONS}

Natural products have played an important part in the treatment of human diseases and most notably, in cancer therapies. Naringin, a flavone glycoside, is promising for the treatment of many diseases due to its low cost, broad availability, long history of use, and variety of pharmacological actions, with the predominant evidence currently focusing on its anticancer impacts. Naringin alone, or combined with other drugs may be useful for treating cancers. Emerging studies showed that naringin-metal complexes have greater anticancer activities compared to free naringin. Naringin can impact several cancer types, including glioblastoma, hepatocellular carcinoma, lung adenocarcinoma, breast cancer, prostate cancer, melanoma, leukemia, colon cancer, gastric cancer, oral cancer, brain cancer, bladder cancer, and ovarian cancer. It has been demonstrated that naringin employs multiple mechanisms to hamper cancer initiation, promotion, and progression via modulation of several dysregulated signaling cascades implicated in inflammation, proliferation, cell survival, apoptosis, autophagy, angiogenesis, invasion, and metastasis (Figure 3). In particular, the cancer-inhibitory effects of naringin have been linked to the regulation of various signaling pathways, such as Nrf2, NF- $\kappa \mathrm{B}, \mathrm{PI} 3 \mathrm{~K} / \mathrm{Akt} / \mathrm{mTOR}$, JNK, ERK, and p38 MAPK. Naringin intervenes with the function of various signaling molecules, such as caspases, Bax, TNF- $\alpha, B c l-2$, VEGF, and ILs. Various patents have shown that naringin can specifically affect desired targets (Table 6), making it

\section{REFERENCES}

Abdulla, M., and Gruber, P. (2000). Role of diet modification in cancer prevention. Biofactors 12, 45-51. doi:10.1002/biof.5520120108

Abotaleb, M., Samuel, S. M., Varghese, E., Varghese, S., Kubatka, P., Liskova, A., et al. (2019). Flavonoids in cancer and apoptosis. Cancers (Basel). 11, 28. doi:10. 3390/cancers11010028

Alam, M. A., Subhan, N., Rahman, M. M., Uddin, S. J., Reza, H. M., and Sarker, S. D. (2014). Effect of citrus flavonoids, naringin and naringenin, on metabolic syndrome and their mechanisms of action. Adv. Nutr. 5, 404-417. doi:10.3945/ an.113.005603

Allott, E. H., Howard, L. E., Vidal, A. C., Moreira, D. M., Castro-Santamaria, R., Andriole, G. L., et al. (2017). Statin use, serum lipids, and prostate inflammation possible to use naringin and its formulations for further investigations for targeted therapies.

The biggest obstacle concerning naringin as a novel therapeutic agent is that current naringin anticancer evidence is focused on in vitro models of cancers, and there are few detailed in vivo studies. Another challenge is related to bioavailability of naringin and selection of a dose range for clinical/therapeutic application based on available preclinical studies. Nevertheless, according to completed and undergoing clinical studies on naringin, bioavailability and effective concentration may not be barrier for exploring its therapeutic benefits. Moreover, since all studies presented in this review utilized pure compounds obtained from various sources, providing a full taxonomic validation of the material under investigation is one of the challenges. The possible restrictions with naringin pharmacokinetics highlight the necessity for the development of novel delivery systems. In particular, further experimental and technological approaches are needed for designing surface-modified naringinnanostructures to attain targeted drug delivery systems toward cancer. The result of research findings as evaluated here might offer substantial support for further development of naringin as a multi-targeted agent for the prevention and intervention of human malignancies.

\section{DATA AVAILABILITY STATEMENT}

The original contributions presented in the study are included in the article/Supplementary Material, further inquiries can be directed to the corresponding authors.

\section{AUTHOR CONTRIBUTIONS}

MF conceived and designed the study. MG-M and MF collected and reviewed the literature as well as extracted and analyzed the data. MGM prepared the first draft of the manuscript and created the figures. MG-M and MF collected additional literature, refined mechanistic figures, edited the manuscript, and suggested improvements. GJ edited the manuscript. $A B$ coordinated this project as well as reviewed and edited the manuscript. All authors have read and approved the final manuscript.

in men with a negative prostate biopsy: results from the REDUCE trial. Cancer Prev. Res. 10, 319-326. doi:10.1158/1940-6207.capr-17-0019

Alwhibi, M. S., Khalil, M. I. M., Ibrahim, M. M., El-Gaaly, G. A., and Sultan, A. S. (2017). Potential antitumor activity and apoptosis induction of Glossostemon bruguieri root extract against hepatocellular carcinoma cells. Evid Based Complement Alternat Med. 2017, 7218562. doi:10.1155/2017/7218562

Amin, A. R. M. R., Kucuk, O., Khuri, F. R., and Shin, D. M. (2009). Perspectives for cancer prevention with natural compounds. Jco, 27, 2712. doi:10.1200/JCO. 2008.20.6235

Aroui, S., Aouey, B., Chtourou, Y., Meunier, A.-C., Fetoui, H., and Kenani, A. (2016a). Naringin suppresses cell metastasis and the expression of matrix metalloproteinases (MMP-2 and MMP-9) via the inhibition of ERK-P38JNK signaling pathway in human glioblastoma. Chem. Biol. Interact. 244, 195. doi:10.1016/j.cbi.2015.12.011 
Aroui, S., Fetoui, H., and Kenani, A. (2020). Natural dietary compound naringin inhibits glioblastoma cancer neoangiogenesis. BMC Pharmacol. Toxicol. 21, 46. doi:10.1186/s40360-020-00426-1

Aroui, S., Najlaoui, F., Chtourou, Y., Meunier, A.-C., Laajimi, A., Kenani, A., et al. (2016b). Naringin inhibits the invasion and migration of human glioblastoma cell via downregulation of MMP-2 and MMP-9 expression and inactivation of p38 signaling pathway. Tumor Biol. 37, 3831. doi:10.1007/s13277-015-4230-4

Ascierto, P. A., Grimaldi, A. M., Acquavella, N., Borgognoni, L., Calabrò, L., Cascinelli, N., et al. (2013). Future perspectives in melanoma research. J. Transl. Med. 14, 323. doi:10.1186/s12967-016-1070-y

Atta, E. M., Hegab, K. H., Abdelgawad, A. A. M., and Youssef, A. A. (2019). Synthesis, characterization and cytotoxic activity of naturally isolated naringin-metal complexes. Saudi Pharm. J. 27, 584. doi:10.1016/j.jsps. 2019.02.006

Ávila-Gálvez, M. Á., Giménez-Bastida, J. A., Espín, J. C., and González-Sarrías, A. (2020). Dietary phenolics against breast cancer. A critical evidence-based review and future perspectives. Ijms 21, 5718. doi:10.3390/ijms21165718

Bai, Y., Peng, W., Yang, C., Zou, W., Liu, M., Wu, H., et al. (2020). Pharmacokinetics and metabolism of naringin and active metabolite naringenin in rats, dogs, humans, and the differences between species. Front. Pharmacol. 11, 364. doi:10.3389/fphar.2020.00364

Banjerdpongchai, R., Wudtiwai, B., and Khawon, P. (2016b). Induction of human hepatocellular carcinoma HepG2 cell apoptosis by naringin. Asian Pac. J. Cancer Prev. 17, 3289-3294. doi:10.14456/apjcp.2016.90/APJCP.2016.17.7. 3289

Banjerdpongchai, R., Wudtiwai, B., Khaw-on, P., Rachakhom, W., Duangnil, N., and Kongtawelert, P. (2016a). Hesperidin from Citrus seed induces human hepatocellular carcinoma HepG2 cell apoptosis via both mitochondrial and death receptor pathways. Tumor Biol. 37, 227. doi:10.1007/s13277-015-3774-7

Basta, A. H., Lotfy, V. F., Ghaly, N. S., Nabil, M., and Mohamed, K. M. (2020). Bioactivity evaluation of amino acid-conjugates with protein versus cellulose based conjugates and extracted flavonoids. J. Drug Deliv. Sci. Tech. 60, 101924. doi:10.1016/j.jddst.2020.101924

Basu, P., and Maier, C. (2018). Phytoestrogens and breast cancer: in vitro anticancer activities of isoflavones, lignans, coumestans, stilbenes and their analogs and derivatives. Biomed. Pharmacother. 107, 1648. doi:10.1016/j. biopha.2018.08.100

Benkovic, V., Horvat Knezevic, A., Brozovic, G., Knezevic, F., Đikic, D., Bevanda, M., et al. (2007). Enhanced antitumor activity of irinotecan combined with propolis and its polyphenolic compounds on Ehrlich ascites tumor in mice. Biomed. Pharmacother. 61, 292. doi:10.1016/j.biopha.2007.02.012

Bharti, S., Rani, N., Krishnamurthy, B., and Arya, D. (2014). Preclinical evidence for the pharmacological actions of naringin: a review. Planta Med. 80, 437. doi:10.1055/s-0034-1368351

Bishayee, A., and Sethi, G. (2016). Bioactive natural products in cancer prevention and therapy: progress and promise. Semin. Cancer Biol. 40-41, 1. doi:10.1016/j. semcancer.2016.08.006

Bracke, M., Vyncke, B., Opdenakker, G., Foidart, J.-M., De Pestel, G., and Mareel, M. (1991). Effect of catechins and citrus flavonoids on invasionin vitro. Clin. Exp. Metast 9, 13. doi:10.1007/BF01831706

Cadoo, K. A., Fornier, M. N., and Morris, P. G. (2013). Biological subtypes of breast cancer: current concepts and implications for recurrence patterns. Q. J. Nucl. Med. Mol. Imaging 57, 312-321.

Cai, L., Wu, H., Tu, C., Wen, X., and Zhou, B. (2018). Naringin inhibits ovarian tumor growth by promoting apoptosis: an in vivo study. Oncol. Lett. 16, 59-64. doi:10.3892/ol.2018.8611

Camargo, C. A., Gomes-Marcondes, M. C., Wutzki, N. C., and Aoyama, H. (2012). Naringin inhibits tumor growth and reduces interleukin-6 and tumor necrosis factor a levels in rats with Walker 256 carcinosarcoma. Anticancer Res. 32, 129.

Campbell, J. K., King, J. L., Harmston, M., Lila, M. A., and Erdman, J. W. (2006). Synergistic effects of flavonoids on cell proliferation in Hepa-1c1c7 and LNCaP cancer cell lines. J. Food Sci. 71, S358. doi:10.1111/j.1750-3841.2006.00013.x

Chen, M., Peng, W., Hu, S., and Deng, J. (2018). miR-126/VCAM-1 regulation by naringin suppresses cell growth of human non-small cell lung cancer. Oncol. Lett. 16, 4754-4760. doi:10.3892/ol.2018.9204

Chen, R., Qi, Q.-L., Wang, M.-T., and Li, Q.-Y. (2016). Therapeutic potential of naringin: an overview. Pharm. Biol. 54, 3203-3210. doi:10.1080/13880209.2016. 1216131
Chen, S., Lin, R., Hu, X., Shi, Q., and Chen, H. (2020). Naringin induces endoplasmic reticulum stress-mediated apoptosis, inhibits $\beta$-catenin pathway and arrests cell cycle in cervical cancer cells. Acta Biochim. Pol. 67, 181-188. doi:10.18388/abp.2020_5182

Chen, Y. C., Shen, S. C., and Lin, H. Y. (2003). Rutinoside at C7 attenuates the apoptosis-inducing activity of flavonoids. Biochem. Pharmacol. 66, 1139. doi:10. 1016/S0006-2952(03)00455-6

Cheng, H., Jiang, X., Zhang, Q., Ma, J., Cheng, R., Yong, H., et al. (2020). Naringin inhibits colorectal cancer cell growth by repressing the PI3K/AKT/mTOR signaling pathway. Exp. Ther. Med. 19, 3798-3804. doi:10.3892/etm.2020.8649

Chidambara Murthy, K. N., Kim, J., Vikram, A., and Patil, B. S. (2012). Differential inhibition of human colon cancer cells by structurally similar flavonoids of citrus. Food Chem. 132, 27. doi:10.1016/j.foodchem.2011.10.014

Cho, K. R., and Shih, I.-M. (2009). Ovarian cancer. Annu. Rev. Pathol. Mech. Dis. 4, 287-313. doi:10.1146/annurev.pathol.4.110807.092246

Choi, J., Lee, D.-H., Jang, H., Park, S.-Y., and Seol, J.-W. (2020). Naringenin exerts anticancer effects by inducing tumor cell death and inhibiting angiogenesis in malignant melanoma. Int. J. Med. Sci. 17, 3049. doi:10.7150/ijms.44804

Choi, M., Fuller, C. D., Thomas, C. R., Jr., and Wang, S. J. (2008). Conditional survival in ovarian cancer: results from the SEER dataset 1988-2001. Gynecol. Oncol. 109, 203-209. doi:10.1016/j.ygyno.2008.01.033

Cragg, G. M., and Pezzuto, J. M. (2016). Natural products as a vital source for the discovery of cancer chemotherapeutic and chemopreventive agents. Med. Princ. Pract. 25, 41-59. doi:10.1159/000443404

Dai, K., Yan, S., Yan, W., Chen, D., and Xu, Z. (2009). Effects of naringin on the proliferation and osteogenic differentiation of human bone mesenchymal stem cell. Eur. J. Pharmacol. 607, 1-5. doi:10.1016/j.ejphar.2009.01.035

Dai, T.-y., Wang, B., Lin, S.-y., Jiang, J.-p., Wu, L.-q., and Qian, W.-b. (2017). Pure total flavonoids from Citrus paradisi Macfad induce leukemia cell apoptosis in vitro. Chin. J. Integr. Med. 23, 370. doi:10.1007/s11655-016-2593-z

Davatgaran-Taghipour, Y., Masoomzadeh, S., Farzaei, M. H., Bahramsoltani, R., Karimi-Soureh, Z., Rahimi, R., et al. (2017). Polyphenol nanoformulations for cancer therapy: experimental evidence and clinical perspective. Ijn, 12, 2689. doi:10.2147/IJN.S131973

Davis, J. C., Daw, N. C., Navid, F., Billups, C. A., Wu, J., Bahrami, A., et al. (2018). 18F-FDG uptake during early adjuvant chemotherapy predicts histologic response in pediatric and young adult patients with osteosarcoma. J. Nucl. Med. 59, 25-30. doi:10.2967/jnumed.117.190595

de Lourdes Mata Bilbao, M., Andreslacueva, C., Jáuregui, O., and Lamuelaraventos, R. (2007). Determination of flavonoids in a Citrus fruit extract by LC-DAD and LC-MS. Food Chem. 101, 1742. doi:10.1016/j.foodchem.2006.01.032

de Oliveira Júnior, R. G., Christiane Adrielly, A. F., da Silva Almeida, J. R. G., Grougnet, R., Thiéry, V., and Picot, L. (2018). Sensitization of tumor cells to chemotherapy by natural products: a systematic review of preclinical data and molecular mechanisms. Fitoterapia 129, 383-400. doi:10.1016/j.fitote.2018. 02.025

Dhuique-Mayer, C., Caris-Veyrat, C., Ollitrault, P., Curk, F., and Amiot, M.-J. (2005). Varietal and interspecific influence on micronutrient contents in citrus from the mediterranean area. J. Agric. Food Chem. 53, 2140. doi:10.1021/ jf0402983

Durgo, K., Vuković, L., Rusak, G., Osmak, M., and Čolić, J. F. (2007). Effect of flavonoids on glutathione level, lipid peroxidation and cytochrome P450 CYP1A1 expression in human laryngeal carcinoma cell lines. Food Technol. Biotechnol. 45, 69-79.

EFSA (2011). Scientific Opinion on the safety and efficacy of naringin when used as a sensory additive for all animal species. EFSA J. 9, 2444. doi:10.2903/j.efsa. 2011.2444

Elansary, H. O., Szopa, A., Kubica, P., Ekiert, H., Klimek-Szczykutowicz, M., ElAnsary, D. O., et al. (2020). Polyphenol profile and antimicrobial and cytotoxic activities of natural Mentha $\mathrm{x}$ piperita and Mentha longifolia populations in Northern Saudi Arabia. Processes 8, 479. doi:10.3390/PR8040479

Elsawy, H., Algefare, A. I., Alfwuaires, M., Khalil, M., Elmenshawy, O. M., Sedky, A., et al. (2020). Naringin alleviates methotrexate-induced liver injury in male albino rats and enhances its antitumor efficacy in HepG2 cells. Biosci. Rep. 40, BSR20193686. doi:10.1042/BSR20193686

Erdogan, S., Doganlar, O., Doganlar, Z. B., and Turkekul, K. (2018). Naringin sensitizes human prostate cancer cells to paclitaxel therapy. Prostate Int. 6, 126. doi:10.1016/j.prnil.2017.11.001 
Fazary, A. E., Ju, Y.-H., Al-Shihri, A. S., Bani-Fwaz, M. Z., Alfaifi, M. Y., Alshehri, M. A., et al. (2017). Platinum and vanadate bioactive complexes of glycoside naringin and phenolates. Open Chem. 15, 189. doi:10.1515/ chem-2017-0022

Feng, L., and Mumper, R. J. (2013). A critical review of lipid-based nanoparticles for taxane delivery. Cancer Lett. 334, 157-175. doi:10.1016/j.canlet.2012.07.006

Ferlay, J., Soerjomataram, I., Dikshit, R., Eser, S., Mathers, C., Rebelo, M., et al. (2015). Cancer incidence and mortality worldwide: sources, methods and major patterns in GLOBOCAN 2012. Int. J. Cancer 136, E359-E386. doi:10.1002/ijc. 29210

Ferreira, L. R., Macedo, J. A., Ribeiro, M. L., and Macedo, G. A. (2013). Improving the chemopreventive potential of orange juice by enzymatic biotransformation. Food Res. Int. 51, 526. doi:10.1016/j.foodres.2013.01.018

Fidler, M. M., Gupta, S., Soerjomataram, I., Ferlay, J., Steliarova-Foucher, E., and Bray, F. (2017). Cancer incidence and mortality among young adults aged 20-39 years worldwide in 2012: a population-based study. Lancet Oncol. 18, 1579-1589. doi:10.1016/s1470-2045(17)30677-0

Garcia, J. P., Lakshmi, B. A., and Kim, S. (2019). Potential anticancer applications of the novel naringin-based ruthenium (II) complex. 3 Biotech. 9, 181. doi:10. 1007/s13205-019-1718-4

Goldman, J. M., and Melo, J. V. (2003). Chronic myeloid leukemia-advances in biology and new approaches to treatment. N. Engl. J. Med. 349, 1451-1464. doi:10.1056/nejmra020777

Gullett, N. P., Ruhul Amin, A. R. M., Bayraktar, S., Pezzuto, J. M., Shin, D. M., Khuri, F. R., et al. (2010). Cancer prevention with natural compounds. Semin. Oncol., 37, 258. doi:10.1053/j.seminoncol.2010.06.014

Gunther, H., and Reinhold, K. (2005). Means and methods for improved cancer treatment based on MDR1. Japan Patent NO JP2005508312A. Japan Patent Office.

Guo, B., Zhang, Y., Hui, Q., Wang, H., and Tao, K. (2016). Naringin suppresses the metabolism of A375 cells by inhibiting the phosphorylation of c-Src. Tumor Biol. 37, 3841. doi:10.1007/s13277-015-4235-z

Habauzit, V., Sacco, S. M., Gil-Izquierdo, A., Trzeciakiewicz, A., Morand, C., Barron, D., et al. (2011). Differential effects of two citrus flavanones on bone quality in senescent male rats in relation to their bioavailability and metabolism. Bone 49, 1108-1116. doi:10.1016/j.bone.2011.07.030

Hajjaji, N., Couet, C., Besson, P., and Bougnoux, P. (2012). DHA effect on chemotherapy-induced body weight loss: an exploratory study in a rodent model of mammary tumors. Nutr. Cancer 64, 1000-1007. doi:10.1080/ 01635581.2012 .714832

Han, L., Tan, J., Li, J., Meng, T., Wang, Y., and Wang, S. (2020). Structurally improved reduced graphene oxide nanocluster structured assembly with Naringin for the effective photothermal therapy of colon tumour patients and nursing care management. Mol. Phys. 118, e1736674. doi:10.1080/ 00268976.2020 .1736674

Hsiao, Y.-C., Hsieh, Y.-S., Kuo, W.-H., Chiou, H.-L., Yang, S.-F., Chiang, W.-L., et al. (2007a). The tumor-growth inhibitory activity of flavanone and $2^{\prime}-\mathrm{OH}$ flavanone in vitro and in vivo through induction of cell cycle arrest and suppression of cyclins and CDKs. J. Biomed. Sci. 14, 107. doi:10.1007/ s11373-006-9117-3

Hsiao, Y.-C., Kuo, W.-H., Chen, P.-N., Chang, H.-R., Lin, T.-H., Yang, W.-E., et al. (2007b). Flavanone and $2^{\prime}-\mathrm{OH}$ flavanone inhibit metastasis of lung cancer cells via down-regulation of proteinases activities and MAPK pathway. Chem. Biol. Interact., 167, 193. doi:10.1016/j.cbi.2007.02.012

Jabri, T., Imran, M., Aziz, A., Rao, K., Kawish, M., Irfan, M., et al. (2019). Design and synthesis of mixed micellar system for enhanced anticancer efficacy of Paclitaxel through its co-delivery with Naringin. Drug Development Ind. Pharm. 45, 703. doi:10.1080/03639045.2018.1550091

Jäger, A., and Saaby, L. (2011). Flavonoids and the CNS. Molecules 16, 1471-1485. doi:10.3390/molecules 16021471

Jayakumar, T., Hsu, C.-Y., Khamrang, T., Hsia, C.-H., Hsia, C.-W., Manubolu, M., et al. (2018). Possible molecular targets of novel ruthenium complexes in antiplatelet therapy. Ijms 19, 1818. doi:10.3390/ijms19061818

Jemal, A., Thomas, A., Murray, T., and Thun, M. (2002). Cancer statistics, 2002. CA: A Cancer J. Clinicians 52, 23-47. doi:10.3322/canjclin.52.1.23

Jessmon, P., Boulanger, T., Zhou, W., and Patwardhan, P. (2017). Epidemiology and treatment patterns of epithelial ovarian cancer. Expert Rev. Anticancer Ther. 17, 427-437. doi:10.1080/14737140.2017.1299575
Jin, C.-Y., Park, C., Lee, J.-H., Chung, K. T., Kwon, T. K., Kim, G.-Y., et al. (2009). Naringenin-induced apoptosis is attenuated by Bcl-2 but restored by the small molecule Bcl-2 inhibitor, HA 14-1, in human leukemia U937 cells. Toxicol. Vitro 23, 259. doi:10.1016/j.tiv.2008.12.005

Jin, Y., Tian, T., Ma, Y., Xu, H., and Du, Y. (2015). Simultaneous determination of ginsenoside $\mathrm{Rb} 1$, naringin, ginsenoside $\mathrm{Rb} 2$ and oridonin in rat plasma by $\mathrm{LC}$ MS/MS and its application to a pharmacokinetic study after oral administration of Weifuchun tablet. J. Chromatogr. B 1000, 112-119. doi:10.1016/j.jchromb. 2015.06.027

Joshi, R., Kulkarni, Y. A., and Wairkar, S. (2018). Pharmacokinetic, pharmacodynamic and formulations aspects of Naringenin: an update. Life Sci. 215, 43. doi:10.1016/j.lfs.2018.10.066

Kabała-Dzik, A., Rzepecka-Stojko, A., Kubina, R., Iriti, M., Wojtyczka, R. D., Buszman, E., et al. (2018). Flavonoids, bioactive components of propolis, exhibit cytotoxic activity and induce cell cycle arrest and apoptosis in human breast cancer cells MDA-MB-231 and MCF-7-A comparative study. Cell. Mol. Biol. 64, 1-10. doi:10.14715/cmb/2018.64.8.1

Kaiserová, H., Šimůnek, T., Van Der Vijgh, W. J. F., Bast, A., and Kvasničková, E. (2007). Flavonoids as protectors against doxorubicin cardiotoxicity: role of iron chelation, antioxidant activity and inhibition of carbonyl reductase. Biochim. Biophys. Acta (BBA)-Mol. Basis Disease 1772, 1065-1074. doi:10.1016/j. bbadis.2007.05.002

Kanno, S.-i., Tomizawa, A., Hiura, T., Osanai, Y., Shouji, A., Ujibe, M., et al. (2005). Inhibitory effects of naringenin on tumor growth in human cancer cell lines and sarcoma S-180-implanted mice. Biol. Pharm. Bull. 28, 527. doi:10.1248/bpb. 28.527

Karami, K., Mehri Lighvan, Z., Farrokhpour, H., Dehdashti Jahromi, M., and Momtazi-borojeni, A. A. (2018). Synthesis and spectroscopic characterization study of new palladium complexes containing bioactive O,O-chelated ligands: evaluation of the DNA/protein BSA interaction, in vitro antitumoural activity and molecular docking. J. Biomol. Struct. Dyn. 36, 3324. doi:10.1080/07391102. 2017.1391125

Kashyap, D., Tuli, H. S., Yerer, M. B., Sharma, A., Sak, K., Srivastava, S., et al. (2021). Natural product-based nanoformulations for cancer therapy: opportunities and challenges. Semin. Cancer Biol. 69, 5-23. doi:10.1016/j. semcancer.2019.08.014

Kawaii, S., Tomono, Y., Katase, E., Ogawa, K., and Yano, M. (1999). HL-60 differentiating activity and flavonoid content of the readily extractable fraction prepared fromCitrusJuices. J. Agric. Food Chem. 47, 128. doi:10. 1021/jf9805101

Kim, D.-H., Jung, E.-A., Sohng, I.-S., Han, J.-A., Kim, T.-H., and Han, M. J. (1998). Intestinal bacterial metabolism of flavonoids and its relation to some biological activities. Arch. Pharm. Res. 21, 17. doi:10.1007/BF03216747

Kim, D.-I., Lee, S.-J., Lee, S.-B., Park, K., Kim, W.-J., and Moon, S.-K. (2008). Requirement for Ras/Raf/ERK pathway in naringin-induced G1-cell-cycle arrest via p21WAF1 expression. Carcinogenesis 29, 1701. doi:10.1093/carcin/ bgn055

Kim, H.-J., Song, J. Y., Park, H. J., Park, H.-K., Yun, D. H., and Chung, J.-H. (2009). Naringin protects against rotenone-induced apoptosis in human neuroblastoma SH-SY5Y cells. Korean J. Physiol. Pharmacol. 13, 281. doi:10. 4196/kjpp.2009.13.4.281

Knežević, A. H., Dikić, D., Lisičić, D., Kopjar, N., Oršolić, N., Karabeg, S., et al. (2011). Synergistic effects of irinotecan and flavonoids on Ehrlich ascites tumour-bearing mice. Basic Clin. Pharmacol. Toxicol. 109, 343-349. doi:10. 1111/j.1742-7843.2011.00735.x

Konno, A., Misaki, M., Toda, J., Wada, T., and Yasumatsu, K. (1982). Bitterness reduction of naringin and limonin by .BETA.-cyclodextrin. Agric. Biol. Chem. 46, 2203-2208. doi:10.1271/bbb1961.46.2203

Krishnakumar, N., Sulfikkarali, N., RajendraPrasad, N., and Karthikeyan, S. (2011). Enhanced anticancer activity of naringenin-loaded nanoparticles in human cervical (HeLa) cancer cells. Biomed. Prev. Nutr. 1, 223. doi:10.1016/j.bionut. 2011.09.003

Kuo, S. M. (1996). Antiproliferative potency of structurally distinct dietary flavonoids on human colon cancer cells. Cancer Lett. 110, 41. doi:10.1016/ S0304-3835(96)04458-8

Kweon, K. H., Lee, C. R., Jung, S. J., Ban, E. J., Kang, S.-W., Jeong, J. J., et al. (2014). Sirtl induction confers resistance to etoposide-induced genotoxic apoptosis in thyroid cancers. Int. J. Oncol. 45, 2065-2075. doi:10.3892/ijo.2014.2585 
Lagoa, R., Silva, J., Rodrigues, J. R., and Bishayee, A. (2020). Advances in phytochemical delivery systems for improved anticancer activity. Biotechnol. Adv. 38, 107382. doi:10.1016/j.biotechadv.2019.04.004

Le Marchand, L., Murphy, S. P., Hankin, J. H., Wilkens, L. R., and Kolonel, L. N. (2000). Intake of flavonoids and lung cancer. J. Natl. Cancer Inst. 92, 154. doi:10. 1093/jnci/92.2.154

Lee, K. W., Bode, A. M., and Dong, Z. (2011). Molecular targets of phytochemicals for cancer prevention. Nat. Rev. Cancer 11, 211. doi:10.1038/nrc3017

Levi, F., Vecchia, C. L., Randimbison, L., and Franceschi, S. (1993). Incidence of infiltrating cancer following superficial bladder carcinoma. Int. J. Cancer 55, 419-421. doi:10.1002/ijc.2910550316

Lewinska, A., Siwak, J., Rzeszutek, I., and Wnuk, M. (2015). Diosmin induces genotoxicity and apoptosis in DU145 prostate cancer cell line. Toxicol. Vitro 29, 417. doi:10.1016/j.tiv.2014.12.005

Li, H., Yang, B., Huang, J., Xiang, T., Yin, X., Wan, J., et al. (2013a). Naringin inhibits growth potential of human triple-negative breast cancer cells by targeting $\beta$-catenin signaling pathway. Toxicol. Lett. 220, 219. doi:10.1016/j. toxlet.2013.05.006

Li, J., Dong, Y., Hao, G., Wang, B., Wang, J., Liang, Y., et al. (2017). Naringin suppresses the development of glioblastoma by inhibiting FAK activity. J. Drug Target. 25, 41. doi:10.1080/1061186X.2016.1184668

Li, P., Wang, S., Guan, X., Liu, B., Wang, Y., Xu, K., et al. (2013b). Acute and 13 weeks subchronic toxicological evaluation of naringin in Sprague-Dawley rats. Food Chem. Toxicol. 60, 1-9. doi:10.1016/j.fct.2013.07.019

Liang, W., Du, G., Zhang, H., Jin, L., Lv, H., Wang, W., et al. (2008). Use of naringenin and naringin as inhibitors of the signaling pathway of transforming growth factor beta1. European patent NO ES2519040T3. European Patent Office.

Liang, W., Zhang, C. L., Zeng, W., Zhang, C., and Wang, L. (2016). Application of naringenin and naringin in tumor radiotherapy. U.S. Patent NO US10307393B2. U.S. Patent and Trademark Office.

Liu, X., Yang, X., Chen, F., and Chen, D. (2017). Combined application of doxorubicin and naringin enhances the antitumor efficiency and attenuates the toxicity of doxorubicin in HeLa cervical cancer cells. Int. J. Clin. Exp. Pathol. 10, 7303-7311.

Luo, H., Jiang, B.-H., King, S. M., and Chen, Y. C. (2008). Inhibition of cell growth and VEGF expression in ovarian cancer cells by flavonoids. Nutr. Cancer 60, 800. doi:10.1080/01635580802100851

Martínez-Vélez, N., Gomez-Manzano, C., Fueyo, J., Patiño-García, A., and Alonso, M. M. (2018). "Oncolytic virotherapy for gliomas: a preclinical and clinical summary," in Gene therapy in neurological disorders (Amsterdam, Netherlands: Elsevier), 357-384.

Meiyanto, E., Hermawan, A., and Anindyajati, A. (2012). Natural products for cancer-targeted therapy: citrus flavonoids as potent chemopreventive agents. Asian Pac. J. Cancer Prev. 13, 427. doi:10.7314/APJCP.2012.13. 2.427

Mellou, F., Loutrari, H., Stamatis, H., Roussos, C., and Kolisis, F. N. (2006). Enzymatic esterification of flavonoids with unsaturated fatty acids: effect of the novel esters on vascular endothelial growth factor release from K562 cells. Process Biochem. 41, 2029. doi:10.1016/j. procbio.2006.05.002

Memariani, Z., Abbas, S. Q., ul Hassan, S. S., Ahmadi, A., and Chabra, A. (2020). Naringin and naringeninin as anticancer agents and adjuvants in cancer combination therapy; efficacy and molecular mechanisms of action, a comprehensive narrative review. Pharmacol. Res., 105264. doi:10.1016/j.phrs. 2020.105264

Menichini, F., Tundis, R., Loizzo, M. R., Bonesi, M., D’Angelo, D., Lombardi, P., et al. (2016). Citrus medica L. cv Diamante (Rutaceae) peel extract improves glycaemic status of Zucker diabetic fatty (ZDF) rats and protects against oxidative stress. J. Enzyme Inhib. Med. Chem. 31, 1270. doi:10.3109/ 14756366.2015.1115400

Menon, L. G., Kuttan, R., and Kuttan, G. (1995). Inhibition of lung metastasis in mice induced by B16F10 melanoma cells by polyphenolic compounds. Cancer Lett. 95, 221. doi:10.1016/0304-3835(95)03887-3

Miller, E. G., Peacock, J. J., Bourland, T. C., Taylor, S. E., Wright, J. M., Patil, B. S., et al. (2008). Inhibition of oral carcinogenesis by citrus flavonoids. Nutr. Cancer 60, 69. doi:10.1080/01635580701616163
Ming, H., Chuang, Q., Jiashi, W., Bin, L., Guangbin, W., and Xianglu, J. (2018). Naringin targets Zeb1 to suppress osteosarcoma cell proliferation and metastasis. Aging 10, 4141. doi:10.18632/aging.101710

Mohamed, E., Abu Hashim, I., Yusif, R., Shaaban, A., El-Sheakh, A., Hamed, M., et al. (2018). Polymeric micelles for potentiated antiulcer and anticancer activities of naringin. IJN 13, 1009. doi:10.2147/IJN.S154325

Moher, D., Liberati, A., Tetzlaff, J., Altman, D. G., and Group, P. (2009). Preferred reporting items for systematic reviews and meta-analyses: the PRISMA statement. Plos Med. 6, e1000097. doi:10.1371/journal.pmed.1000097

Myers, C. (1998). The role of iron in doxorubicin-induced cardiomyopathy. Semin. Oncol. 25, 10.

Neuhouser, M. L. (2004). Review: dietary flavonoids and cancer risk: evidence from human population studies. Nutr. Cancer 50, 1-7. doi:10.1207/ s15327914nc5001_1

Newman, D. J., and Cragg, G. M. (2012). Natural products as sources of new drugs over the 30 years from 1981 to 2010. J. Nat. Prod. 75, 311. doi:10.1021/ np200906s

Newman, D. J., and Cragg, G. M. (2020). Natural products as sources of new drugs over the nearly four decades from 01/1981 to 09/2019. J. Nat. Prod. 83, 770. doi:10.1021/acs.jnatprod.9b01285

Nie, Y.-c., Wu, H., Li, P.-b., Xie, L.-m., Luo, Y.-l., Shen, J.-g., et al. (2012). Naringin attenuates EGF-induced MUC5AC secretion in A549 cells by suppressing the cooperative activities of MAPKs-AP-1 and IKKs-I $\kappa \mathrm{B}-\mathrm{NF}-\kappa \mathrm{B}$ signaling pathways. Eur. J. Pharmacol. 690, 207. doi:10.1016/j.ejphar.2012.06.040

Ooghe, W. C., Ooghe, S. J., Detavernier, C. 1. M., and Huyghebaert, A. (1994). Characterization of orange juice (Citrus sinensis) by flavanone glycosides. J. Agric. Food Chem. 42, 2183-2190. doi:10.1021/jf00046a020

Oršolić, N., Benković, V., Lisičić, D., Dikić, D., Erhardt, J., and Knežević, A. H. (2010). Protective effects of propolis and related polyphenolic/flavonoid compounds against toxicity induced by irinotecan. Med. Oncol. 42, 1346-1358. doi:10.1007/s12032-009-9387-5

Oršolić, N., Štajcar, D., and Bašić, I. (2009). Propolis and its flavonoid compounds cause cytotoxicity on human urinary bladder transitional cell carcinoma in primary culture. Period. Biol. 111, 113-121.

Özyürek, M., Akpınar, D., Bener, M., Türkkan, B., Güçlü, K., and Apak, R. (2014). Novel oxime based flavanone, naringin-oxime: synthesis, characterization and screening for antioxidant activity. Chem. Biol. Interact. 212, 40. doi:10.1016/j. cbi.2014.01.017

Park, J. H., Jin, C.-Y., Lee, B. K., Kim, G.-Y., Choi, Y. H., and Jeong, Y. K. (2008). Naringenin induces apoptosis through downregulation of Akt and caspase-3 activation in human leukemia THP-1 cells. Food Chem. Toxicol. 46, 3684. doi:10.1016/j.fct.2008.09.056

Pennathur, A., Gibson, M. K., Jobe, B. A., and Luketich, J. D. (2013). Oesophageal carcinoma. The Lancet 381, 400-412. doi:10.1016/s0140-6736(12)60643-6

Pereira, R., Andrades, N., Paulino, N., Sawaya, A., Eberlin, M., Marcucci, M., et al. (2007). Synthesis and characterization of a metal complex containing naringin and $\mathrm{Cu}$, and its antioxidant, antimicrobial, antiinflammatory and tumor cell cytotoxicity. Molecules 12, 1352. doi:10.3390/12071352

Persky, M. J., Persky, V., Setchell, K. D., and Barnes, S. (1994). Soy intake and cancer risk: a review of the in vitro and in vivo data. Nutr. Cancer 21, 113. doi:10. 1080/01635589409514310

Pfaendler, K. S., and Tewari, K. S. (2016). Changing paradigms in the systemic treatment of advanced cervical cancer. Am. J. Obstet. Gynecol. 214, 22-30. doi:10.1016/j.ajog.2015.07.022

Puranik, N. V., Srivastava, P., Bhatt, G., John Mary, D. J. S., Limaye, A. M., and Sivaraman, J. (2019). Determination and analysis of agonist and antagonist potential of naturally occurring flavonoids for estrogen receptor (ERa) by various parameters and molecular modelling approach. Sci. Rep. 9, 7450. doi:10. 1038/s41598-019-43768-5

Raha, S., Kim, S. M., Lee, H. J., Yumnam, S., Saralamma, V. V., Ha, S. E., et al. (2020). Naringin induces lysosomal permeabilization and autophagy cell death in AGS gastric cancer cells. Am. J. Chin. Med. 48, 679. doi:10.1142/ S0192415X20500342

Raha, S., Yumnam, S., Hong, G. E., Lee, H. J., Saralamma, V. V. G., Park, H.-S., et al. (2015). Naringin induces autophagy-mediated growth inhibition by downregulating the PI3K/Akt/mTOR cascade via activation of MAPK pathways in AGS cancer cells. Int. J. Oncol. 47, 1061. doi:10.3892/ijo.2015.3095 
Rajadurai, M., and Stanely Mainzen Prince, P. (2007). Preventive effect of naringin on isoproterenol-induced cardiotoxicity in Wistar rats: an in vivo and in vitro study. Toxicology 232, 216-225. doi:10.1016/j.tox.2007.01.006

Rajamani, S., Radhakrishnan, A., Sengodan, T., and Thangavelu, S. (2018). Augmented anticancer activity of naringenin-loaded TPGS polymeric nanosuspension for drug resistive MCF-7 human breast cancer cells. Drug Development Ind. Pharm. 44, 1752. doi:10.1080/03639045.2018.1496445

Ramanathan, R., Tan, C. H., and Das, N. P. (1992). Cytotoxic effect of plant polyphenols and fat-soluble vitamins on malignant human cultured cells. Cancer Lett. 62, 217. doi:10.1016/0304-3835(92)90099-H

Ramesh, E., and Alshatwi, A. A. (2013). Naringin induces death receptor and mitochondria-mediated apoptosis in human cervical cancer ( $\mathrm{SiHa}$ ) cells. Food Chem. Toxicol. 51, 97. doi:10.1016/j.fct.2012.07.033

Ravishankar, D., Rajora, A. K., Greco, F., and Osborn, H. M. I. (2013). Flavonoids as prospective compounds for anti-cancer therapy. Int. J. Biochem. Cell Biol. 45, 2821-2831. doi:10.1016/j.biocel.2013.10.004

Real, H. J. V., Alfaia, A. J., Calado, A. R. T., and Ribeiro, M. H. L. (2007). High pressure-temperature effects on enzymatic activity: naringin bioconversion. Food Chem. 102, 565-570. doi:10.1016/j.foodchem.2006.05.033

Reddy, L., Odhav, B., and Bhoola, K. D. (2003). Natural products for cancer prevention: a global perspective. Pharmacol. Ther. 99, 1-13. doi:10.1016/s01637258(03)00042-1

Rivoira, M. A., Rodriguez, V., Talamoni, G., and de Talamoni, N. T. (2020). New perspectives in the pharmacological potential of naringin in medicine. Curr. Med. Chem. doi:10.2174/0929867327666200604171351

Romagnolo, D. F., and Selmin, O. I. (2012). Flavonoids and cancer prevention: a review of the evidence. J. Nutr. Gerontol. Geriatr. 31, 206-238. doi:10.1080/ 21551197.2012.702534

Rout, G. K., Shin, H.-S., Gouda, S., Sahoo, S., Das, G., Fraceto, L. F., et al. (2018). Current advances in nanocarriers for biomedical research and their applications. Artif. Cell Nanomedicine, Biotechnol. 46, 1053-1062. doi:10. 1080/21691401.2018.1478843

Said-Elbahr, R., Nasr, M., Alhnan, M. A., Taha, I., and Sammour, O. (2016). Nebulizable colloidal nanoparticles co-encapsulating a COX-2 inhibitor and a herbal compound for treatment of lung cancer. Eur. J. Pharm. Biopharm. 103, 1. doi:10.1016/j.ejpb.2016.03.025

Sangodkar, J., Katz, S., Melville, H., and Narla, G. (2010). Lung adenocarcinoma: lessons in translation from bench to bedside. Mt Sinai J. Med. 77, 597-605. doi:10.1002/msj.20226

Sangubotla, R., Anantha Lakshmi, B., Kim, S., and Kim, J. (2020). Bio-inspired green fluorescent gold-naringin nanoclusters as a dual-functional optical probe for bio-imaging and intracellular sensing applications. Appl. Surf. Sci. 510, 145417. doi:10.1016/j.apsusc.2020.145417

Schindler, R., and Mentlein, R. (2006). Flavonoids and vitamin E reduce the release of the angiogenic peptide vascular endothelial growth factor from human tumor cells. J. Nutr. 136, 1477. doi:10.1093/jn/136.6.1477

Selvaraj, S., Krishnaswamy, S., Devashya, V., Sethuraman, S., and Krishnan, U. M. (2014). Investigations on the membrane interactions of naringin and its complexes with copper and iron: implications for their cytotoxicity. RSC Adv. 4, 46407. doi:10.1039/c4ra08157a

Seyfried, T. N., and Shelton, L. M. (2010). Cancer as a metabolic disease. Nutr. Metab. 7, 7. doi:10.1186/1743-7075-7-7

Sheikh, I., Sharma, V., Tuli, H. S., Aggarwal, D., Sankhyan, A., Vyas, P., et al. (2021). Cancer chemoprevention by flavonoids, dietary polyphenols and terpenoids. Biointerface Res. Appl. Chem. 11, 8502-8537. doi:10.33263/ BRIAC111.85028537

Shen, S.-C., Ko, C. H., Tseng, S.-W., Tsai, S.-H., and Chen, Y.-C. (2004). Structurally related antitumor effects of flavanones in vitro and in vivo: involvement of caspase 3 activation, p21 gene expression, and reactive oxygen species production. Toxicol. Appl. Pharmacol. 197, 84. doi:10.1016/j. taap.2004.02.002

Siegel, R., Naishadham, D., and Jemal, A. (2013). Cancer statistics, 2013. CA: A Cancer J. Clinicians 63, 11-30. doi:10.3322/caac.21166

Singh, B., Rani, M., Singh, J., Moudgil, L., Sharma, P., Kumar, S., et al. (2016). Identifying the preferred interaction mode of naringin with gold nanoparticles through experimental, DFT and TDDFT techniques: insights into their sensing and biological applications. RSC Adv. 6, 79470. doi:10.1039/c6ra12076h
So, F. V., Guthrie, N., Chambers, A. F., Moussa, M., and Carroll, K. K. (1996). Inhibition of human breast cancer cell proliferation and delay of mammary tumorigenesis by flavonoids and citrus juices. Nutr. Cancer 26, 167. doi:10. 1080/01635589609514473

Sreepriya, M., and Bali, G. (2005). Chemopreventive effects of embelin and curcumin against N-nitrosodiethylamine/phenobarbital-induced hepatocarcinogenesis in Wistar rats. Fitoterapia 76, 549-555. doi:10.1016/j. fitote.2005.04.014

Steiner, C., Arnould, S., Scalbert, A., and Manach, C. (2008). Isoflavones and the prevention of breast and prostate cancer: new perspectives opened by nutrigenomics. Br. J. Nutr. 99, ES78-ES108. doi:10.1017/ s0007114508965788

Surampalli, G., K. Nanjwade, B., and Patil, P. A. (2015). Corroboration of naringin effects on the intestinal absorption and pharmacokinetic behavior of candesartan cilexetil solid dispersions usingin-siturat models. Drug Development Ind. Pharm. 41, 1057-1065. doi:10.3109/03639045.2014.925918

Syed, A. A., Reza, M. I., Shafiq, M., Kumariya, S., Singh, P., Husain, A., et al. (2020). Naringin ameliorates type 2 diabetes mellitus-induced steatohepatitis by inhibiting RAGE/NF- $\mathrm{kB}$ mediated mitochondrial apoptosis. Life Sci. 257, 118118. doi:10.1016/j.lfs.2020.118118

Tajaldini, M., Samadi, F., Khosravi, A., Ghasemnejad, A., and Asadi, J. (2020). Protective and anticancer effects of orange peel extract and naringin in doxorubicin treated esophageal cancer stem cell xenograft tumor mouse model. Biomed. Pharmacother., 121, 109594. doi:10.1016/j.biopha.2019.109594

Tan, T.-W., Chou, Y.-E., Yang, W.-H., Hsu, C.-J., Fong, Y.-C., and Tang, C.-H. (2014). Naringin suppress chondrosarcoma migration through inhibition vascular adhesion molecule-1 expression by modulating miR-126. Int. Immunopharmacol. 22, 107. doi:10.1016/j.intimp.2014.06.029

Tang, J., Kong, D., Bu, L., and Wu, G. (2017). Surgical management for follicular variant of papillary thyroid carcinoma. Oncotarget 8, 79507. doi:10.18632/ oncotarget. 18525

Thangavel, P., and Vaiyapuri, M. (2013). Antiproliferative and apoptotic effects of naringin on diethylnitrosamine induced hepatocellular carcinoma in rats. Biomed. Aging Pathol. 3, 59. doi:10.1016/j.biomag.2013.01.006

Thornalley, P. J. (2008). Protein and nucleotide damage by glyoxal and methylglyoxal in physiological systems-role in ageing and disease. Drug Metabol. Drug Interact. 23, 125. doi:10.1515/dmdi.2008.23.1-2.125

Torre, L. A., Bray, F., Siegel, R. L., Ferlay, J., Lortet-Tieulent, J., and Jemal, A. (2015). Global cancer statistics, 2012. CA: A Cancer J. Clinicians 65, 87-108. doi: $10.3322 /$ caac. 21262

Tsai, Y.-J., and Tsai, T.-H. (2012). Mesenteric lymphatic absorption and the pharmacokinetics of naringin and naringenin in the rat. J. Agric. Food Chem. 60, 12435-12442. doi:10.1021/jf301962g

Ugocsai, K., Varga, A., Molnár, P., Antus, S., and Molnár, J. (2005). Effects of selected flavonoids and carotenoids on drug accumulation and apoptosis induction in multidrug-resistant colon cancer cells expressing MDR1/LRP. In vivo $60,433-438$.

Van der Jeught, K. V. d., Xu, H.-C., Li, Y.-J., Lu, X.-B., and Ji, G. (2018). Drug resistance and new therapies in colorectal cancer. Wjg 24, 3834. doi:10.3748/ wjg.v24.i34.3834

Vanamala, J., Leonardi, T., Patil, B. S., Taddeo, S. S., Murphy, M. E., Pike, L. M., et al. (2006). Suppression of colon carcinogenesis by bioactive compounds in grapefruit. Carcinogenesis 27, 1257. doi:10.1093/carcin/bgi318

Vardiman, J. W., Thiele, J., Arber, D. A., Brunning, R. D., Borowitz, M. J., Porwit, A., et al. (2009). The 2008 revision of the World Health Organization (WHO) classification of myeloid neoplasms and acute leukemia: rationale and important changes. Blood 114, 937-951. doi:10.1182/blood-2009-03-209262

Wong, N., Tucker, J., and Mccaffrey, D. R. (2006). Treatment of diseases associated with the egr-1 enhancer element. South Korea Patent NO KR20060120101A Office. doi:10.7591/9781501711480

Wu, X., Huang, Z., Liu, J., Chen, Y., Huang, H., He, Y., et al. (2019). Effects and mechanism of inhibition of naringin in combination with atorvastatin on prostate cancer cells in vitro and in vivo. Phytochemistry Lett. 32, 168. doi:10. 1016/j.phytol.2019.06.008

Xie, D., Yuan, P., Wang, D., Jin, H., and Chen, H. (2017). Effects of naringin on the expression of miR-19b and cell apoptosis in human hepatocellular carcinoma. Oncol. Lett. 14, 1455-1459. doi:10.3892/ol.2017.6278 
Yadav, A., Kumar, R., Sunkaria, A., Singhal, N., Kumar, M., and Sandhir, R. (2016). Evaluation of potential flavonoid inhibitors of glyoxalase-I based on virtual screening and in vitro studies. J. Biomol. Struct. Dyn. 34, 993. doi:10.1080/ 07391102.2015.1064830

Yamane, K., and Kato, Y. (2012). Handbook on flavonoids: dietary sources, properties and health benefits. Hauppauge, NY: Nova Science Publishers.

Yang, C. S., Landau, J. M., Huang, M.-T., and Newmark, H. L. (2001). Inhibition ofcarcinogenesis bydietarypolyphenoliccompounds. Annu. Rev. Nutr., 21, 381. doi:10.1146/annurev.nutr.21.1.381

Yang, Y., Tao, B., Gong, Y., Chen, R., Yang, W., Lin, C., et al. (2020). Functionalization of $\mathrm{Ti}$ substrate with $\mathrm{pH}$-responsive naringin- $\mathrm{ZnO}$ nanoparticles for the reconstruction of large bony after osteosarcoma resection. J. Biomed. Mater. Res. 108, 2190. doi:10.1002/jbm.a.36977

Yen, H.-R., Liu, C.-J., and Yeh, C.-C. (2015). Naringenin suppresses TPA-induced tumor invasion by suppressing multiple signal transduction pathways in human hepatocellular carcinoma cells. Chem. Biol. Interact. 235, 1. doi:10.1016/j.cbi.2015.04.003

Yoshinaga, A., Kajiya, N., Oishi, K., Kamada, Y., Ikeda, A., Chigwechokha, P. K., et al. (2016). NEU3 inhibitory effect of naringin suppresses cancer cell growth by attenuation of EGFR signaling through GM3 ganglioside accumulation. Eur. J. Pharmacol. 782, 21. doi:10.1016/j.ejphar.2016.04.035

Zeng, L., Zhen, Y., Chen, Y., Zou, L., Zhang, Y., Hu, F., et al. (2014). Naringin inhibits growth and induces apoptosis by a mechanism dependent on reduced activation of NF- $\mathrm{B} / \mathrm{COX}-2$-caspase-1 pathway in HeLa cervical cancer cells. Int. J. Oncol. 45, 1929. doi:10.3892/ijo.2014.2617

Zeng, X., Su, W., Zheng, Y., He, Y., He, Y., Rao, H., et al. (2019). Pharmacokinetics, tissue distribution, metabolism, and excretion of naringin in aged rats. Front. Pharmacol. 10, 34. doi:10.3389/fphar.2019.00034

Zhang, J., Gao, W., Liu, Z., Zhang, Z., and Liu, C. (2014). Systematic analysis of main constituents in rat biological samples after oral administration of the methanol extract of fructus aurantii by HPLC-ESI-MS/MS. Iran J. Pharm. Res. 13, 493.

Zhang, L., Xu, X., Jiang, T., Wu, K., Ding, C., Liu, Z., et al. (2018a). Citrus aurantium naringenin prevents osteosarcoma progression and recurrence in the patients who underwent osteosarcoma surgery by improving antioxidant capability. Oxid. Med. Cell. Longevity 2018, 8713263. doi:10.1155/2018/8713263

Zhang, Y.-S., Wang, F., Cui, S.-X., and Qu, X.-J. (2018b). Natural dietary compound naringin prevents azoxymethane/dextran sodium sulfate-induced chronic colorectal inflammation and carcinogenesis in mice. Cancer Biol. Ther. 19, 735. doi:10.1080/15384047.2018.1453971
Zhou, J.-L., Fang, X.-Y., Wang, J.-Q., Zhao, L.-G., Li, Y., Tang, F., et al. (2018). Structures and bioactivities of seven flavonoids from Osmanthus fragrans "Jinqiu" essential oil extraction residues. Nat. Product Res. 32, 588. doi:10. 1080/14786419.2017.1318387

Zhou, J., Xia, L., and Zhang, Y. (2019). Naringin inhibits thyroid cancer cell proliferation and induces cell apoptosis through repressing PI3K/AKT pathway. Pathol. Res. Pract. 215, 152707. doi:10.1016/j.prp.2019.152707

Zhu, H., Gao, J., Wang, L., Qian, K. J., and Cai, L. P. (2018). In vitro study on reversal of ovarian cancer cell resistance to cisplatin by naringin via the nuclear factor- $\kappa \mathrm{B}$ signaling pathway. Exp. Ther. Med. 14, 2643-2648. doi:10.3892/etm. 2018.5695

Zhu, H., Zou, X., Wan, J., Wang, L., Qian, K.-J., Cai, L.-P., et al. (2017). Reversal of cisplatin resistance in ovarian cancer cells mediated by naringin-induced COX2 expression through the NF- $\mathrm{kB}$ signaling pathway. Int. J. Clin. Exp. Med. 10, 7590-7596.

Zhu, J., Huang, Y., Zhang, J., Feng, Y., and Shen, L. (2020). Formulation, preparation and evaluation of nanostructured lipid carrier containing naringin and coix seed oil for anti-tumor application based on "unification of medicines and excipients". DDDT 14, 1481. doi:10.2147/ DDDT.S236997

Zi, X., and Simoneau, R. (2004). Treatment of bladder and urinary tract cancers. U.S. Patent NO US7326734B2. U.S. Patent and Trademark Office.

Zivancevic-Simonovic, S., Mihaljevic, O., Kostic, I., Ilic, N., Mihajlovic, D., Vasiljevic, D., et al. (2017). Eosinophil cationic protein in patients with differentiated thyroid cancer treated with radioactive iodine 131. Ann. Clin. Lab. Sci. 47, 541-545.

Conflict of Interest: The authors declare that the research was conducted in the absence of any commercial or financial relationships that could be construed as a potential conflict of interest.

Copyright (c) 2021 Ghanbari-Movahed, Jackson, Farzaei and Bishayee. This is an open-access article distributed under the terms of the Creative Commons Attribution License (CC BY). The use, distribution or reproduction in other forums is permitted, provided the original author(s) and the copyright owner(s) are credited and that the original publication in this journal is cited, in accordance with accepted academic practice. No use, distribution or reproduction is permitted which does not comply with these terms. 